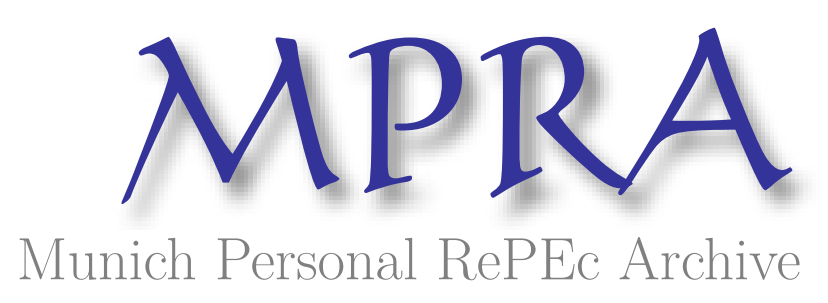

\title{
Centralizing Disconnected Markets? An Irrelevance Result
}

Wittwer, Milena

1 February 2017

Online at https://mpra.ub.uni-muenchen.de/76534/

MPRA Paper No. 76534, posted 02 Feb 2017 22:55 UTC 


\title{
Centralizing Disconnected Markets? An Irrelevance Result* Milena Wittwer ${ }^{\dagger}$
}

February 1, 2017

\begin{abstract}
This article compares centralized with disconnected markets in which $n>2$ strategic agents trade two perfectly divisible goods. In a multi-goods uniform-price double auction (centralized market) traders can make their demand for one good contingent on the price of the other good. Interlinking demands across goods is - by design - not possible when each good is traded in separate, single-good uniform-price double auctions (disconnected market). Here, agents are constrained in the way they can submit their joint preferences. I show for a class of models that equilibrium allocations and efficiency of centralized and disconnected markets nevertheless coincide when the total supply of the goods is known or perfectly correlated. This suggests that disconnected markets perform as well as centralized markets when the underlying uncertainty that governs the goods' market prices is perfectly correlated.
\end{abstract}

Keywords: Disconnected markets, divisible goods, multi-unit double auctions, trading JEL classification: D44, D47, D82, G14

Modern economies consist of markets with different structures. Some markets are centralized. They offer multiple goods within the same platform. Some others are disconnected in that only one good is sold or traded per platform. Notably, many goods can be purchased or traded in either centralized or disconnected markets. Different spectrum frequencies are auctioned in a centralized (combinatorial) auction, as in the FCC auction, yet also in separate (non-combinatorial) auctions. Mineral rights, oil and gas royalties, dairy products and aquarian animals are each offered in global, centralized online platforms, ${ }^{1}$ but can also be purchased in separate markets that sell only milk, not butter, or only one species of fish, for instance. Furthermore, different financial securities are traditionally traded in separate auctions, one for each security (e.g. OTC market, NYSE); while modern online platforms organize exchanges of different securities within the same market. In such a centralized market participants are allowed to demand and offer packages of the goods. Interlinking preferences across goods is by design not possible when each good is traded in a separate market. A dealer who bids for the 3-month German bond, for example, cannot make his choice contingent on the price of the 1-year French bond. More generally, agents are constrained in the way they can display their joint preferences for the goods when markets are disconnected. They cannot freely maximize their gains from trade. Intuitively, the degree of efficiency is bound to hinge on the market's structure (centralized or disconnected). I show that this need not be the case. When the residual supplies of the goods are perfectly correlated the equilibrium allocation of disconnected markets is identical to the allocation of a centralized market. My counter-intuitive finding suggests that the market structure may be irrelevant when the underlying uncertainty that governs the strategic pricing process for each good is perfectly correlated.

*For helpful discussions and comments, I thank Robert Wilson, Mohammad Akbarpour, Peter Cramton, Darrell Duffie, David K. Levine, Paul Milgrom and all participants of his seminar.

†European University Institute, milena.wittwer@eui.eu.

${ }^{1}$ Examples of such platforms are: TheMinearlAuction, Global Dary Trade, Aquabid. 
The irrelevance result provides guidance for the design of markets. While new technology has made it feasible to centralize separated markets, integrating them remains challenging for policy makers. They face national and institutional constraints. What is more, centralization often requires cross-border collaboration, further complicating the integration process. In general, combining disconnected markets involves some cost: some are transitory (like learning costs to adapt to a new system), some others are permanent. Existing ownership structures have to be broken. Market makers who centralize the system (intermediaries) take away parts of the total surplus, and might even distort the outcome by their strategic manipulations. My irrelevance result suggests when it is not worthwhile to pay these costs, because such policy intervention would have no or negligible effects on both the volume of trade and efficiency. It also helps one to understand why some markets remain disconnected even though centralization has long become technologically feasible. The markets of equity and fixed income securities are good examples. These are identical products which are traded in dozens of trading venues, none with dominating market shares. Why does the market structure not converge towards centralization? My result suggests a simple answer. The gains from market integration are not high enough to force changes in the existing market structure, because the fundamentals that drive the price for these identical products are highly correlated.

In the model, $n>2$ agents, each with an independent private type, have joint-preferences over two perfectly divisible goods with fixed or random total supply. These goods are traded in either a centralized or disconnected market. The later consists of two standard uniform-price double auctions which are run simultaneously for each good. In each auction agents submit demand schedules specifying a price for each quantity they demand or supply. The market clears at the price where aggregate demand meets aggregate supply, and each agent buys or sells what he demanded or offered at this price. When the market is centralized an agent is allowed to bid for bundles. More precisely, the rules of the standard uniform-price double auction are extended to allow the demand for one good to depend on the price of the other good. Holding all other rules of the game fixed allows me to focus on the effect of centralizing disconnected markets. If I were to compare the separate uniform-price auctions to some other combinatorial auction, I would no longer be able to separate the effect of centralization from those coming from changes of other rules of the transaction. The irrelevance result then builds on a comparison of the traded equilibrium quantities across market structures. These are the equilibrium allocations of an ex-post equilibrium, whenever one exists, and of a symmetric Bayesian Nash equilibrium otherwise.

My research topic fits into the literature that compares the performance of decentralized, or fragmented, markets with centralized markets. Decentralized markets are typically studied in (i) search (ii) bargaining or (iii) network models. Most contributions highlight different types of inefficiencies in decentralized markets. Using search theory, Miao (2006), for instance, shows that social welfare improves with monopolistic market making (i); Elliott and Nava (2015) argue in favor of centralized clearinghouses to resolve pervasive inefficiencies of disconnected matching markets (ii); while Elliott (2015) extends Kranton and Minehart (2001)'s pioneering network model of trade to quantify the efficiency losses (iii). In setting up an auction model, I take a different 
perspective on decentralized markets than previous studies (i-iii). With the disconnected market consisting of simultaneous multi-unit auctions, it relates to a growing literature put forward by computer scientists. Motivated by Bikhchandani (1999), who warned that "simultaneous sealed bid auctions are likely to be inefficient under incomplete information" (p. 212), they quantify the efficiency of simultaneous auctions of heterogeneous goods by computing the "price of anarchy" (=the maximum ratio between the social welfare under an optimal allocation and the welfare at an equilibrium). While, most work concentrates on single-item auctions (e.g. Feldman et al. (2015a)), Syrgkanis and Tardos (2013) show that $m$ simultaneously run uniform-price auctions achieve "at least" $\frac{e-1}{4 e} \approx 0.158$ of the expected optimal effective welfare. ${ }^{2}$ Malamud and Rostek (2014)'s findings are orthogonal to this literature. In independent work, they develope a framework that is similar to mine to study the potential of decentralizing the exchange of financial securities to improve efficiency. ${ }^{4}$ They show that it can be strictly welfare improving to break up a centralized structure, modeled as a multi-asset uniform-price double auction. In their model, any change in market structure affects efficiency.

Coming from many different directions and using a wide variety of techniques, all of these articles agree that social welfare in centralized and decentralized markets differs. My Irrelevance Theorem goes against this broad consensus. Even though it is specific to particular applications, it is in the spirit of famous general theorems that tell us when "market structure" in different formats is irrelevant: Sah and Stiglitz (1987) and Dasgupta (1988) establish conditions under which the number of firms (=market structure) does not matter for technological innovation; Modigliani and Miller (1958) prove that the financial structure of the firm (=market structure) does not necessarily matter for the creation of value; Weber (1983) shows that the realized price of any auction game that sells identical objects (=market structure) is the realized price of the previous auction; and Vickery (1961) proves that some rules of the auction (=market structure) are irrelevant for the seller's expected revenue. Building on the Revenue Equivalence Theorem, Biais (1993) then demonstrates that centralized and fragmented markets with risk-averse agents who compete for a single market order (=market structure) may give rise to the same expected ask (bid) price.

My main methodological contribution belongs to the literature on multi-unit auctions of perfectly divisible goods. I rely on existing research on multi-unit auctions with perfectly divisible goods, so called "share auctions". 3 Share auctions were introduced by Wilson (1979) for single-sided transactions, and closely relate to Klemperer and Meyer (1989), Kyle (1989), Vives (2011), Rostek and Weretka (2012)'s work on uniform-price double auctions. More specifically, I draw on insights by Du and Zhu (2012), whose framework has been used in other articles in the finance literature (e.g. Duffie and Zhu (2016)). They make assumptions on the traders' utility functions that allow

\footnotetext{
${ }^{2}$ Feldman et al. (2015b) suggest that such inefficiency washes out in the limit as markets grow large. This is a different environment than studied in this paper, where strategic pricing decisions of individual agents have an impact on the outcome.

${ }^{3}$ Similar to the frequent assumption in the literature on single-unit auctions that the set of available prices is dense, the assumption of perfect divisibility is a continuous approximation of a discrete set of quantities - which across economic disciplines has long been recognized as a valuable alternative when discrete problems are intractable (Woodward (2015)). With imperfect divisibility of goods or buyers who can submit only a maximal amount of bids the analysis becomes more complex due to discontinuities and rationing. This has been demonstrated recently by Horaçsu and McAdams (2010) and Kastl (2011, 2012).
} 
them to solve for ex-post equilibria of an isolated uniform-price double auction, as well as a multiassets double auction. My ex-post equilibria are derived based on the same assumptions.

This literature typically considers an auction in isolation neglecting possible interconnections across auction markets. While we have some understanding of how agents behave in multi-unit auctions that trade or sell either one good, or multiple goods within the same transaction, the existing published literature is - to the best of my knowledge - silent about strategic incentives of agents that participate in separate multi-unit auctions that offer related goods. ${ }^{4}$ My necessary optimality condition for the Bayesian Nash equilibrium of this complex game holds for a broad class of utilities and any differentiable distribution functions and enables me to explain the strategic incentives that lie behind the equilibrium. Moreover, it has a straight-forward extension to the other most frequently used (sealed-bid) multi-unit auction format, the pay-as-bid auction.

The remainder of the article is structured as follows. Having set-up the model in section 1, section 2 explains equilibrium behavior. A comparison of equilibrium allocations across market structures and informational assumptions leads to the Irrelevance Theorem stated in section 3. Section 4 concludes.

Throughout the article I denote random variables is bold.

\section{Framework}

There are $n>2$ agents, ${ }^{5}$ each with a private iid type $\boldsymbol{s}_{\boldsymbol{i}}$, who trade two perfectly divisible goods, indexed $m=1,2$, in a centralized market or disconnected market. The centralized market is modeled as a multi-good uniform-price double auction, the disconnected market consist of two separate single-good uniform-price double auctions which are run simultaneously. Total supply in each market is either random (benchmark case) or fixed. In general I make no further distributional assumptions, with one exception. In order to obtain a linear Bayesian Nash equilibrium candidate in the disconnected auction with random supply I follow the standard simplifying assumption of the literature and let all random variables be normally distributed. ${ }^{6}$ More precisely, $\left(\begin{array}{l}\boldsymbol{Q}_{\mathbf{2}} \\ \boldsymbol{Q}_{\mathbf{2}}\end{array}\right) \sim N\left(\left(\begin{array}{c}\mu_{1} \\ \mu_{2}\end{array}\right),\left(\begin{array}{cc}\sigma^{2} & \rho \sigma^{2} \\ \rho \sigma^{2} & \sigma^{2}\end{array}\right)\right)$ and $\boldsymbol{s}_{\boldsymbol{i}} \sim N\left(\mu_{s}, \sigma_{s}^{2}\right)$ iid across $i$ and w.r.t. $\boldsymbol{Q}_{\mathbf{1}}, \boldsymbol{Q}_{\mathbf{2}}$.

Each agent submits a pair of differentiable bidding schedules

$$
\begin{array}{rlrl}
b_{i, m}\left(\cdot, s_{i}\right): \mathbb{R} \rightarrow \mathbb{R} & \text { for } m=1,2 & & \text { in disconnected auctions } \\
\bar{b}_{i, m}\left(\cdot, \cdot, s_{i}\right): \mathbb{R}^{2} \rightarrow \mathbb{R} \text { for } m=1,2 & & \text { in centralized auction }
\end{array}
$$

These are inverse demand schedules, assumed to be decreasing in their first argument. The demand functions are denoted by $x_{i, m}\left(\cdot, s_{i}\right)$ and $\bar{x}_{i, m}\left(\cdot, \cdot, s_{i}\right)$.

\footnotetext{
${ }^{4}$ Independent to my own work Malamud, Rostek and Yoon are currently working on a related paper.

${ }^{5}$ With $n=2$ agents the non-existence of equilibria has long been recognized in the literature when marginal utility is decreasing (e.g. Kyle (1989) from Ausubel et al. (2014), Du and Zhu (2016)).

${ }^{6}$ See, for instance, Kyle (1989), Vives (2011), Rostek and Weretka (2012), who all impose a normal distributions.
} 
Once all agents have submitted their demands, the market for good $m$ clears (MC) at price $p_{m}^{*}$ where aggregate demand meets total supply. Each agent buys or sells what he asked for at this price, abbreviated by

$$
\begin{array}{lll}
q_{i, m}^{*} & \equiv x_{i, m}\left(p_{m}^{*}, s_{i}\right) \quad \stackrel{(\mathrm{MC})}{=} Q_{m}-\sum_{j \neq i} x_{j, m}\left(p_{m}^{*}, s_{j}\right) & \text { in disconnected auctions } \\
\bar{q}_{i, m}^{*} \equiv \bar{x}_{i, m}\left(\bar{p}_{m}^{*}, \bar{p}_{-m}^{*}, s_{i}\right) \stackrel{(\mathrm{MC})}{=} Q_{m}-\sum_{j \neq i} \bar{x}_{j, m}\left(\bar{p}_{m}^{*}, \bar{p}_{-m}^{*}, s_{j}\right) & \text { in centralized auction }
\end{array}
$$

for $m=1,2,-m \neq m$. He makes a total payment of

$$
\begin{aligned}
& T P\left(p_{1}^{*}, p_{2}^{*}, q_{i, 1}^{*}, q_{i, 2}^{*}\right) \equiv p_{1}^{*} q_{i, 1}^{*}+p_{2}^{*} q_{i, 2}^{*} \quad \text { in disconnected auctions } \\
& \overline{\operatorname{TP}}\left(\bar{p}_{1}^{*}, \bar{p}_{2}^{*}, \bar{q}_{i, 1}^{*}, \bar{q}_{i, 2}^{*}\right) \equiv \bar{p}_{1}^{*} \bar{q}_{i, 1}^{*}+\bar{p}_{2}^{*} \bar{q}_{i, 2}^{*} \quad \text { in centralized auction }
\end{aligned}
$$

In order to determine the optimal strategy, each agent maximizes his net payoff. It is defined as the total utility the agent receives from the goods minus his total payment. Purchasing quantities $\left\{q_{1}, q_{2}\right\}$ he receives a utility of

$$
U\left(q_{1}, q_{2}, s_{i}\right)=\sum_{m=1,2}\left\{s_{i} q_{m}-\frac{1}{2} \lambda q_{m}^{2}\right\}-\delta q_{1} q_{2} \quad \text { where } \lambda>0,|\delta| \leq \lambda .
$$

This utility function is simple and intuitive: From winning amount $q_{m}$ the agent obtains a marginal value $s_{i}$. Holding an "inventory" $q_{m}$ of the illiquid asset is costly for the trader. He pays a cost of $\frac{1}{2} \lambda q_{m}^{2} \cdot{ }^{7}$ It may be related to regulatory capital or collateral requirements, or represent an expected cost of being forced to raise liquidity by quickly disposing of remaining inventory into an illiquid market (Duffie and Zhu (2016)). When $\delta \neq 0$, the utility function displays an additional factor: $\delta q_{1} q_{2}$. Its meaning is best understood by analyzing the agent's partial utility of $q_{m}$

$$
\frac{\partial U\left(q_{1}, q_{2}, s_{i}\right)}{\partial q_{m}}=s_{i}-\lambda q_{m}-\delta q_{-m} \quad \text { for } m=1,2 ;-m \neq m
$$

This partial utility is the agent's "true marginal willingness to pay" for a quantity $q_{m}$ given that he obtains quantity $q_{-m}$. It decreases in the amount of good $m(\lambda>0)$, and decreases or increases in the quantity of the other good $-m$ depending on the sign of $\delta$. This parameter measures the relation across goods. Whenever $\delta>0$ the agent is willing to pay less for any given amount $q_{m}$, the more he purchases of good $-m$. The goods are substitutes. They are perfect substitutes when $\delta=\lambda$. Then the marginal utility decreases by the same amount regardless of which good the agent purchases. On the other hand, when $\delta<0$, the agent values the same quantity $q_{m}$ more, the more he owns of the other good $-m$. In this case, goods are complements. Setting $\delta=0$ I could shut down any interconnection between goods to be back to the case of an isolated auction. However, this case is uninteresting. With no relation between the goods there are no strategic effects across goods. The allocation of the centralized and disconnected market trivially coincides. I therefore focus on $\delta \neq 0$ throughout the article.

\footnotetext{
${ }^{7}$ This quadratic cost is common in the literature. It is used by Vives (2011), Rostek and Weretka (2012), Duffie and Zhu (2016) and others.
} 
It is this simple functional form of the utility function that makes the model tractable. In particular, a linear marginal willingness to pay with deterministic slope coefficients gives rise to a linear equilibrium, without constraining the strategy space to linear functions. My optimality conditions for the equilibrium in the simultaneous double auctions, however, holds for any utility function that is, continuous, twice differentiable and has continuous cross-partial derivatives.

I focus on pure-strategy equilibria in which all agents are active in both markets. Whenever possible I solve for the ex-post equilibrium.

Definition 1. An ex post equilibrium is a profile of strategies such that there exists no profile of types or total supply for which some agent would have an incentive to deviate.

Such equilibria are Bayesian Nash equilibria which are robust in the sense that no agent wishes he would have chosen differently once all uncertainty resolves. This is because every agent would choose the same strategy even if he could observe the private types of all of his competitors and the total amount for sale. Nobody regrets his choice ex-post. This implies that we do not need to worry about strategic effects of a secondary (or after) market. Such markets are prominent in particular in the finance sector. Anticipating of such effects could ruin the equilibrium when taken into account.

In disconnected auctions with random total supply, there is no ex-post equilibrium. Here I look for a pure-strategy Bayesian Nash Equilibrium (BNE). It is linear thanks to the additional assumption that random variables are normally distributed.

Definition 2. A symmetric pure-strategy BNE is a pair $\left\{b_{1}\left(\cdot, s_{i}\right), b_{2}\left(\cdot, s_{i}\right)\right\}$ that $\forall i \in I$

$$
\max _{b_{i, 1}\left(\cdot, s_{i}\right), b_{i, 2}\left(\cdot, s_{i}\right)} \mathbb{E}\left[U\left(\boldsymbol{q}_{\boldsymbol{i}, \mathbf{1}}^{\boldsymbol{*}}, \boldsymbol{q}_{\boldsymbol{i}, \mathbf{2}}^{\boldsymbol{*}}, s_{i}\right)\right]-\mathbb{E}\left[T P\left(\boldsymbol{p}_{\mathbf{1}}^{\boldsymbol{*}}, \boldsymbol{p}_{\mathbf{2}}^{\boldsymbol{*}}, \boldsymbol{q}_{\boldsymbol{i}, \mathbf{1}}^{\boldsymbol{*}}, \boldsymbol{q}_{\boldsymbol{i}, \mathbf{2}}^{\boldsymbol{*}}\right)\right] \text { with } \boldsymbol{p}_{\boldsymbol{m}}^{\boldsymbol{*}}=b_{i, m}\left(\boldsymbol{q}_{\boldsymbol{i}, \boldsymbol{m}}^{\boldsymbol{*}}, s_{i}\right)
$$

when $b_{j, m}\left(\cdot, s_{j}\right)=b_{m}\left(\cdot, s_{j}\right) \forall j \neq i, m=1,2$.

\section{Equilibria}

I now state, compare and explain the equilibrium strategies in the different environments. I start by describing how traders choose their equilibrium demand schedules. Understanding how choices are made lays the ground for the Irrelevance Theorem. Since equilibria will be linear, I derive the intuition for this case. More precisely, I give conditions that characterize a linear Bayesian Nash Equilibrium. It is the ex-post equilibrium in the centralized market, and the disconnected auctions with fixed supply. More general optimality conditions for the disconnected auctions are given in Appendix 7.1. These hold under very mild assumptions on the functional form of the utility and distribution functions. 
Disconnected Auction 1: Let all other agents $j \neq i$ play the equilibrium strategies $\left\{b_{1}\left(\cdot, s_{j}\right), b_{2}\left(\cdot, s_{j}\right)\right\}$. Take the perspective of agent $i$ who considers how to to bid in the auction for good 1. Assume he behaves in auction 2 as he will in equilibrium $b_{2}\left(\cdot, s_{i}\right)$. He knows that this makes him win $\boldsymbol{q}_{\boldsymbol{i}, \boldsymbol{2}}^{\boldsymbol{*}}$, implicitly characterized by market clearing

$$
\boldsymbol{q}_{\boldsymbol{i}, \mathbf{2}}^{\boldsymbol{*}}=\boldsymbol{Q}_{\mathbf{2}}-\sum_{j \neq i} x_{2}\left(\boldsymbol{p}_{2}^{*}, \boldsymbol{s}_{\boldsymbol{j}}\right) \text { with } \boldsymbol{p}_{2}^{*}=b_{2}\left(\boldsymbol{q}_{\boldsymbol{i}, \mathbf{2}}^{*}, s_{i}\right)
$$

However, since both auctions take place simultaneously and the bidder neither knows the types of his competitors $\boldsymbol{s}_{-\boldsymbol{i}}$ nor the total supply $\boldsymbol{Q}_{\mathbf{2}}$ ex-ante, he does not know how much he will win in auction 2, when choosing his strategy in auction 1. In that auction, he takes the submitted demand schedules of all others as given. What count for his choice is not the total, but the residual supply

$$
\begin{aligned}
R S_{1}\left(p_{1}, \boldsymbol{s}_{-\boldsymbol{i}}, \boldsymbol{Q}_{\mathbf{1}}\right) & =\boldsymbol{Q}_{\mathbf{1}}-\sum_{j \neq i} x_{j, 1}\left(p_{1}, \boldsymbol{s}_{\boldsymbol{j}}\right) & & \text { in price-quantity space } \\
q_{1} & =\boldsymbol{Q}_{\mathbf{1}}-\sum_{j \neq i} x_{j, 1}\left(p_{1}^{R S}\left(q_{1}, \boldsymbol{s}_{-\boldsymbol{i}}, \boldsymbol{Q}_{\mathbf{1}}\right), \boldsymbol{s}_{\boldsymbol{j}}\right) & & \text { in quantity-price space }
\end{aligned}
$$

It is continuous and upward-sloping by the assumption that all bidding functions are continuous and decreasing. Moreover, since $\boldsymbol{s}_{-\boldsymbol{i}}$ and $\boldsymbol{Q}_{\mathbf{1}}$ are random, the residual supply is random. This makes it difficult for the agent. If he knew the realization of the supply, he would simply pick the point on the residual supply curve that maximizes his net payoff. To determine his optimal price offers, he goes through all possible realizations of the residual supply curve for good $1, p_{1}^{R S}\left(q_{1}, s_{-i}, Q_{1}\right)$. The optimal bid-offer $b_{1}\left(q_{1}, s_{i}\right)$ equates its expected marginal utility with its expected marginal payment:

$$
\mathbb{E}\left[\frac{\partial U\left(q_{1}, \boldsymbol{q}_{\boldsymbol{i}, \mathbf{2}}^{*}, s_{i}\right)}{\partial q_{1}} \mid q_{1}\right]=\mathbb{E}\left[\frac{\partial T P\left(p_{1}^{R S}\left(q_{1}, s_{-i}, Q_{1}\right), \boldsymbol{p}_{\mathbf{2}}^{*}, q_{1}, \boldsymbol{q}_{\boldsymbol{i}, \mathbf{2}}^{*}\right)}{\partial q_{1}} \mid q_{1}\right]
$$

and clears the market: $p_{1}^{R S}\left(q_{1}, s_{-i}, Q_{1}\right)=b_{1}\left(q_{1}, s_{i}\right)$. Hereby, the agent takes the best guess about how much he will obtain in the other auction, by taking the conditional expectation.

Notice that when equilibrium strategies are linear, the slopes of the residual supply curves are deterministic. The right-hand-side is thus independent of $s_{-i}, Q_{1}, Q_{2}$. The analogous holds for the centralized auction.

Centralized Auction: In search for the optimal strategy, the agent now goes through all possible pairs of realizations of residual supply curves $\left\{\bar{p}_{1}^{R S}\left(q_{1}, q_{2}, s_{-i}, Q_{1}\right), \bar{p}_{2}^{R S}\left(q_{2}, q_{1}, s_{-i}, Q_{2}\right)\right\}$. Say a particular pair realizes and that offering prices $\left\{\bar{b}_{1}\left(q_{1}, q_{2}, s_{i}\right), \bar{b}_{2}\left(q_{2}, q_{1}, s_{i}\right)\right\}$ makes agent $i$ win $\left\{q_{1}, q_{2}\right\}$. For each bid offer to be optimal it must be that marginal utility from winning the bid, that is winning $q_{m}$, must equate the marginal payment:

$$
\left[\frac{\partial U\left(q_{1}, q_{2}, s_{i}\right)}{\partial q_{m}}\right]=\left[\frac{\partial \overline{T P}\left(\bar{p}_{1}^{R S}\left(q_{1}, q_{2}, s_{-i}, Q_{1}\right), \bar{p}_{2}^{R S}\left(q_{2}, q_{1}, s_{-i}, Q_{2}\right), q_{1}, q_{2}\right)}{\partial q_{m}}\right]
$$

for both goods $m=1,2$, and clear both markets simultaneously: $\bar{b}_{1}\left(q_{1}, q_{2}, s_{i}\right)=\bar{p}_{1}^{R S}\left(q_{1}, s_{-i}, Q_{1}\right)$, $\bar{b}_{2}\left(q_{2}, q_{1}, s_{i}\right)=\bar{p}_{2}^{R S}\left(q_{2}, q_{1}, s_{-i}, Q_{2}\right)$. 
This condition characterizes the equilibrium strategy $\left\{b_{1}\left(\cdot, \cdot, s_{i}\right), b_{2}\left(\cdot, \cdot, s_{i}\right)\right\}$ point-wise for all $q_{1}, q_{2}$, giving rise to the following lemma. It is a variant of $\mathrm{Du}$ and $\mathrm{Zhu}(2012)$ 's Proposition $3{ }^{8}$

Lemma 1 (Centralized market). There is an ex-post equilibrium, in which all traders are active in both markets. Traders submit for $m=1,2,-m \neq m$

$$
\bar{b}_{m}\left(q_{m}, q_{-m}, s_{i}\right)=s_{i}-\left(\frac{n-1}{n-2}\right)\left\{\lambda q_{m}+\delta q_{-m}\right\}
$$

In equilibrium each agent shades his true marginal willingness to pay $\frac{\partial U\left(q_{1}, q_{2}, s_{i}\right)}{\partial q_{m}}=s_{i}-\lambda q_{m}-\delta q_{-m}$. This strategic behavior is commonly known as "demand-reduction" from standard multi-unit auctions that sell (here trade) one good, given agents have demand for multiple units (see Ausubel et al. (2014)). It carries over to the case of multiple goods where the true demand is multi - (here two -) dimensional.

The equilibrium strategy of a centralized auction is very similar to the strategy of the disconnected auctions when total supply is fixed. ${ }^{8}$

Lemma 2 (Disconnected markets with known supply). There is an ex-post equilibrium in which all traders are active in both markets. Traders submit for $m=1,2,-m \neq m$

$$
b_{m}\left(q_{m}, s_{i}\right)=\bar{b}_{m}\left(q_{m}, q_{m}, s_{i}\right)+\left(\frac{\delta}{n}\right)\left(Q_{m}-Q_{-m}\right)
$$

In a disconnected auction, the price offer for good $m$ can - by design - not depend on the amount the agents has of good $-m$. The agent is forced to substitute $q_{-m}$ in $\bar{b}_{m}\left(q_{m}, q_{-m}, s_{i}\right)$ by $q_{m}$. This means that he can no longer interlink his submitted demands explicitly. What he can do however, is to make his submitted demand in market $m$ dependent on the total supply of the other market, $Q_{-m}$. This allows the agent to implicitly interlink his submitted demand across markets, even though the market rules prevent him from explicitly connecting his preferences. Formally, we observe that the optimal strategy displays a correction term: $C\left(Q_{m}, Q_{-m}, \delta\right) \equiv\left(\frac{\delta}{n}\right)\left(Q_{m}-Q_{-m}\right)$. It can be expressed in terms of equilibrium winning quantities, $q_{i, m}^{*}=\left(\frac{1}{\lambda+\delta}\right)\left(\frac{n-2}{n-1}\right)\left(s_{i}-\frac{1}{n} \sum_{i} s_{i}\right)+\frac{1}{n} Q_{m}$, for $m$ and $-m: C\left(Q_{m}, Q_{-m}, \delta\right)=\delta\left(q_{i, m}^{*}-q_{i,-m}^{*}\right)$. Doing so we see that it corrects for differences in the equilibrium allocation.

When total supply is unknown to the traders, it is no longer possible to condition the submitted demand on the total amount for sale. Therewith the traders loose this option to implicitly interconnect the two markets.

\footnotetext{
${ }^{8}$ When the agent has a type with a common value component: $\gamma s_{i}+\kappa \sum_{j \neq i} s_{j}$ with $\gamma+(n-1) \kappa=1$, as in Du and Zhu (2012), the ex-post equilibrium of Lemma 1 is

$$
\bar{b}_{m}\left(q_{m}, q_{-m}, s_{i}\right)=s_{i}-\left(\frac{n-1}{n \gamma-2}\right)\left\{\lambda q_{m}+\delta q_{m}-\kappa Q_{m}\right\} \text { for } m=1,2 ;-m \neq m
$$

Lemma 2 remains.
} 
Lemma 3 (Disconnected market with random supply). Define $\rho^{i}(\alpha) \equiv \frac{\alpha^{2}(n-1) \sigma_{s}^{2}+\rho \sigma^{2}}{\alpha^{2}(n-1) \sigma_{s}^{2}+\sigma^{2}}$.

In a symmetric Bayesian Nash equilibrium, where all are active in both markets, traders submit for $m=1,2,-m \neq m$

$$
\begin{aligned}
b_{m}^{B N E}\left(q_{m}, s_{i}\right)=\epsilon(\alpha)+\alpha s_{i}-\beta(\alpha) q_{m} \text { with } \alpha & =1-\delta \alpha\left(\frac{1}{n}\right)(n-1)\left[1-\rho^{i}(\alpha)\right] \\
\beta(\alpha) & =\left(\frac{n-1}{n-2}\right)\left(\lambda+\delta \rho^{i}(\alpha)\right) \\
\epsilon(\alpha) & =\delta\left(\frac{1}{n}\right)\left[\left(\rho^{i}(\alpha) \mu_{m}-\mu_{-m}\right)+\alpha(n-1) \mu_{s}\left[1-\rho^{i}(\alpha)\right]\right]
\end{aligned}
$$

With random supply, the agent no longer knows how much he will win in the other auction $\boldsymbol{q}_{\boldsymbol{i},-\boldsymbol{m}}^{*}$ when choosing his demand schedule in action $m$. He cannot correct for the exact difference in the winning quantities. Yet, he does exploits the correlation across residual supplies, that is - by market clearing - his winning quantities. This is the reason for which the correlation of winning quantities, $\rho^{i}(\alpha)$, now plays a key role in his bidding choice. Otherwise, his strategy is similar to when supply is known. This is easy to see when comparing the coefficients of the linear bidding functions of Lemma 2 and Lemma 3 (Figure 1). Moreover, when reproducing the case of fixed supply by degenerating the distribution of total supply ( $\operatorname{setting} \sigma=0, \mu_{1}=Q_{2}, \mu_{2}=Q_{2}$ ), the $\mathrm{BNE}$ is the ex-post equilibrium: $b_{m}\left(\cdot, s_{i}\right)=b_{m}^{B N E}\left(\cdot, s_{i}\right)$.

Figure 1: In disconnected auctions agents submit $\alpha s_{i}-\beta(\alpha) q_{m}+\epsilon(\alpha)$

\begin{tabular}{l|l}
\hline Lemma 2: Ex-post equi (known supply) & Lemma 3: BNE (random supply) \\
\hline$\alpha=1$ & $\alpha=1-\delta \alpha\left(\frac{1}{n}\right)(n-1)\left[1-\rho^{i}(\alpha)\right]$ \\
$\beta=\left(\frac{n-1}{n-2}\right)(\lambda+\delta)$ & $\beta(\alpha)=\left(\frac{n-1}{n-2}\right)\left(\lambda+\delta \rho^{i}(\alpha)\right)$ \\
$\epsilon=\delta\left(\frac{1}{n}\right)\left[Q_{m}-Q_{-m}\right]$ & $\epsilon(\alpha)=\delta\left(\frac{1}{n}\right)\left[\left(\rho^{i}(\alpha) \mu_{m}-\mu_{-m}\right)+\alpha(n-1) \mu_{s}\left(1-\rho^{i}(\alpha)\right)\right]$ \\
\hline
\end{tabular}

\section{Irrelevance Theorem}

A comparison of the equilibrium allocation across market structures leads to the Irrelevance Theorem. It is counter-intuitive. In the centralized market, traders with joint preferences over the goods for sale are allowed to bid for bundles and can therewith jointly maximize their total surplus. Instead, in a disconnected market, their demand schedule can only depend on the price of the security traded in that market. By design of the transaction, agents are always constrained in the way they can display their preferences. One would therefore expect that the equilibrium allocation of the centralized market must differ from the one of the disconnected market. 
Irrelevance Theorem. The equilibrium allocations of centralized and disconnected markets

(i) coincide iff the total amount for sale is known to all traders, or the total amount is uncertain but perfectly correlated across goods, and

(ii) approach one another as $\sigma \rightarrow 0$ or $\rho \rightarrow 1$.

To understand why the market structure can be irrelevant (statement $(i)$ ), recall the intuition that was laid out to explain equilibrium behavior. While preferences are two-dimensional a the submitted demand is one-dimensional in a disconnected auction. The agent picks an optimal point on each possible supply curve, taking the expectation of what will happen in the other market (condition (8)). On the contrary, in the centralized auction the agent is free to pick a pair of points on each pair of realizations of residual supply curves (condition (9)). In choosing how much he trades of one good the agents knows exactly how much he will trade of the other good. There is no need to take an expectation. This means that the trader can make a relatively "better informed" decision in the centralized market, unless the residual supply curves are perfectly correlated. In my set-up where all traders participate in both markets, this case occurs either with fixed or random but perfectly correlated total supply (=condition $(i)$ ). Then a realization of the residual supply curve of good 1, which corresponds to some optimal choice for good 1, maps one-to-one to some realization of the curve of good 2, which in turn corresponds to an optimal choice in auction 2 . Conditional on observing the realization in auction 1, the agent knows exactly how much he will win in the other auction 2. The inherent constraint that he faces in an disconnected auction becomes irrelevant. He deals with the same amount of uncertainty in either market structure. As a consequence, efficiency measures such as the social welfare or the total volume of trade coincide. The result is robust for almost perfectly correlated residual supply curves (statement (ii)).

This intuition should generalize to many other environments that are not considered on a formal level. Say there is some underlying uncertainty about good $m$. It could come from private, affiliated or common values of strategic market participants, it could also be driven by noise traders, or unknown total supply. The key is that, for given strategies of the other agents, there is some aggregate random variable $\boldsymbol{Z}_{\boldsymbol{m}}$ which governs the decision process of market participants and therewith the residual supply for good $m: R S_{m}\left(p_{m}, \boldsymbol{Z}_{\boldsymbol{m}}\right)$. Whenever $\boldsymbol{Z}_{\mathbf{1}}$ is perfectly correlated $Z_{2}$, the residual supply curves of both goods move 1 -to- 1 . In that case, the equilibrium allocation of the disconnected market should be identical to the centralized market. The market structure would not matter. 


\section{Conclusion}

I provide a novel Irrelevance Theorem. It shows under which conditions strategic traders with joint preferences over bundles of goods trade the exact same amount in disconnected and centralized markets. Only in the later they can freely represent their true two-dimensional preferences. I argue that the inherent constraint that agents face in a disconnected market is non-binding whenever the underlying uncertainty that drives pricing decisions is perfectly correlated across markets. In that case there is no informational differences that could lead to differences in allocations of the two market structures.

Besides broad significance for the design of trading markets, my findings could have concrete policy implications. Recently Budish et al. (2015) proposed to reform high-frequency trading markets. They advocate to replace the continuous limit order book which causes an inefficient race in highfrequency trading with frequently held batch uniform-price double auctions. Their model only has one good and thus abstracts from strategic substitution, or arbitrage effects across markets. Such effects could in principle have adverse consequences on the equilibrium dynamics. My irrelevance result tells us when we do not have to care about cross-market effects.

In future work, I aim to generalize the theorem to apply in more environments. In addition, my general first-order conditions of the disconnected auctions serves as theoretic foundation for a related empirical project. In collaboration with Jason Allen and Jakub Kastl I structurally estimate the interdependencies in primary dealer's demand for government securities with different maturities in pay-as-bid auctions. 


\section{References}

Ausubel, L. M., Cramton, P., Pycia, M., Rostek, M., and Weretka, M. (2014). Demand reduction and inefficiency in multi-unit auctions. The Review of Economic Studies, 81(4):1366-1400.

Biais, B. (1993). Price formation and equilibrium liquidity in fragmented and centralized markets. The Journal of Finance, 48(1):157-185.

Bikhchandani, S. (1999). Auctions of heterogeneous objects. Games of Economic Behavior, 26(2):193-220.

Budish, E., Cramton, P., and Shim, J. (2015). The highfrequency trading arms race: Frequent batch auctions as a market design response. The Quarterly Journal of Economics, 130(4):1547-1621.

Dasgupta, P. (1988). Pattents priority and imitation, or, The economies of races and waiting games. Economic Journal, 98:66-80.

Du, S. and Zhu, H. (2012). Ex post equilibria in double auctions of divisible assets. Working paper, Stanford University.

Du, S. and Zhu, H. (2016). Bilateral trading in divisible double auctions. Working paper.

Duffie, D. and Zhu, H. (2016). Size discovery. Review of Financial Studies, forthcoming.

Elliott, M. (2015). Inefficiencies in networked markets. American Economic Journal: Microeconomics, $7(4): 43-82$.

Elliott, M. and Nava, F. (2015). Decentralized bargaining: Efficiency and the core. Working paper, Cambridge University and LSE.

Feldman, M., Fu, H., Gravin, N., and Lucier, B. (2015a). Simultaneous auctions without complements are (almost) efficient. Games and Economic Behavior, pages $1-15$.

Feldman, M., Immorlica, N., Lucier, B., Roughgarden, T., and Syrgkanis, V. (2015b). The price of anarchy in large games. Working paper.

Horaçsu, A. and McAdams, D. (2010). Mechanism choice and strategic bidding in divisible good auctions: An empirical analysis of the turkish treasury auction market. Journal of Political Economy, 118(5):833-865.

Kastl, J. (2011). Discrete bids and empirical inference in divisible good auctions. Review of Economic Studies, 78:974-1014.

Kastl, J. (2012). On the properties of equilibria in pri- vate value divisible good auctions with constrained bidding. Journal of Mathematical Economics, 48:339352.

Klemperer, P. D. and Meyer, M. A. (1989). Supply function equilibria in oligopoly under uncertainty. Econometrica, 57(6):1243-1277.

Kranton, R. E. and Minehart, D. F. (2001). A theory of buyer-seller networks. The American Economic Review, 91(3):485-508.

Kyle, A. S. (1989). Informed speculation with imperfect competition. The Review of Economic Studies, 56(3):317-355.

Malamud, S. and Rostek, M. (2014). Decentralized exchange. Working paper, Swiss Finance Institute and University of Wisconsin-Madison.

Miao, J. (2006). A search model of centralized and decentralized trade. Review of Economic Dynamics, pages 68-92.

Modigliani, F. and Miller, M. (1958). The cost of capital, corporation finance and the theory of investment. American Economic Review, 48(3):261-297.

Rostek, M. and Weretka, M. (2012). Price inferences in small markets. Econometrica, 80(2):687-711.

Sah, R. and Stiglitz, J. E. (1987). The invariance of market innovation to the number of firms. RAND Journal of Economics, 18:98-1008.

Syrgkanis, V. and Tardos, E. (2013). Composable and efficient mechanisms. Proceedings of the forty-fifth annual ACM symposium on Theory of computing, pages 211-220.

Vickery, W. (1961). Counterspeculation, auctions, and competitive sealed tenders. Journal of Finance, 16:837.

Vives, X. (2011). Strategic supply function competition with private information. Econometrica, 76(6):19191966.

Weber, R. (1983). Multi-object auctions. In EngelbrechtWiggans, R. Shubik, M. and R. Stark, editors (1983) Auctions, Bidding and Contracting. New York University Press, New York.

Wilson, R. (1979). Auctions of shares. The Quarterly Journal of Economics, 93(4):675-689.

Woodward, K. L. (2015). In Defense of Pay-as-Bid Auctions: A Divisible-Good Perspective. $\mathrm{PhD}$ thesis, University of California. 


\section{Appendix}

\section{Proof of Lemma 1}

The proof holds for the more general utility function (used by Du and Zhu (2012)):

$$
U\left(v_{i}, q_{1}, q_{2}\right)=\sum_{m=k, l}\left\{v_{i} q_{m}-\frac{1}{2} \lambda q_{m}^{2}\right\}-\delta q_{1} q_{2} \quad \text {, with } \quad v_{i}=\gamma s_{i}+\kappa \sum_{j \neq i} s_{j}
$$

where $\lambda>0,|\delta| \leq \lambda, \gamma, \kappa \geq 0$ and normalization $\gamma+(n-1) \kappa=1$.

It is analogous to Du and Zhu (2012)'s proof of proposition 3. There is one key differences in our set-up. I allow total supply to be random, while Du and Zhu (2012) assume that the total amount for sale is fixed. To account for this difference it suffices to let agent $i$ go through all possible realizations of the residual supply instead of all realization of type profiles of his competitors $s_{-i}$ in Du and Zhu (2012)'s proof. The algebra remains unchanged, which is why I do not reproduce the proof here. The reader is referred to Du and Zhu (2012) pp. 26-27.

The ex-post equilibrium expressed in the price-quantity space is

$$
\bar{b}_{m}\left(q_{m}, q_{-m}, s_{i}\right)=s_{i}-\left(\frac{n-1}{n \gamma-2}\right)\left\{\lambda q_{m}+\delta q_{m}-\kappa Q_{m}\right\}
$$

\section{Proof of Lemma 2}

The proof is written for the more general utility function (13), while I only consider the case of independent private values, that is $\kappa=0, \gamma=1$, in the text. It has two main parts. I first derive an equilibrium candidate (section 6.1). Then I verify that there is no profitable deviation (section 6.2). The algebraic derivations of both parts are in section 6.3.

\subsection{Deriving an equilibrium candidate}

Take the perspective of agent $i$ and fix a profile of private types $\left(s_{1}, \ldots, s_{n}\right) \equiv\left(s_{i}, s_{-i}\right)$. Assume that all other agents play strategy $\left\{x_{1}\left(\cdot, s_{j}\right), x_{2}\left(\cdot, s_{j}\right)\right\}$. Agent $i$ trades against two fixed residual supply curves

$$
R S_{m}^{i}\left(p_{m}, s_{-i}\right)=Q_{m}-\sum_{j \neq i} x_{m}\left(p_{m}, s_{j}\right) \text { for } m=k, l
$$

His task is to pick an optimal point on each curve. In other words, he chooses a price that lies on this residual supply curve in each market. He does so maximizing his payoff of winning $\left\{q_{1}, q_{2}\right\}=\left\{R S_{1}^{i}\left(p_{1}, s_{-i}\right), R S_{2}^{i}\left(p_{2}, s_{-i}\right)\right\}$ at prices $\left\{p_{1}, p_{2}\right\}$.

$$
\max _{p_{1}, p_{2}} \pi\left(v_{i}, p_{1}, p_{2}\right)=\max _{p_{1}, p_{2}}\left(U\left(v_{i}, q_{1}, q_{2}\right)-\sum_{m=k, l} p_{m} q_{m}\right) \quad \text { with } q_{m}=R S_{m}^{i}\left(p_{m}, s_{-i}\right) \text { for } m=k, l
$$


Inserting the assumed form of the utility function (13) the agent's maximization problem reads $\max _{p_{1}, p_{2}} \sum_{m=k, l}\left\{\left(\gamma s_{i}+\kappa \sum_{j \neq i}-p_{m}\right) R S_{m}^{i}\left(p_{m}, s_{-i}\right)-\frac{1}{2} \lambda\left(R S_{m}^{i}\left(p_{m}, s_{-i}\right)\right)^{2}\right\}-\delta R S_{1}^{i}\left(p_{1}, s_{-i}\right) R S_{2}^{i}\left(p_{2}, s_{-i}\right)$

For $m=k, l$ and $m \neq m$, the first-order conditions are

$0=-x_{i, m}\left(p_{m}^{*}, s_{-i}\right)+\left(\gamma s_{i}+\kappa \sum_{j \neq i} s_{j}-p_{m}-\lambda x_{i, m}\left(p_{m}^{*}, s_{-i}\right)-\delta x_{i,-m}\left(p_{-m}^{*}, s_{-i}\right)\right)\left(\left.\frac{\partial R S_{m}^{i}\left(p_{m}, s_{-i}\right)}{\partial p_{m}}\right|_{p_{m}=p_{m}^{*}}\right)$

where I have already used market clearing at the optimum, i.e. $R S_{m}^{i}\left(p_{m}^{*}, s_{-i}\right)=x_{i, m}\left(p_{m}^{*}, s_{i}\right)$ for $m=k, l$. They characterize the optimal price pair $\left\{p_{1}^{*}, p_{2}^{*}\right\}$, or equivalently the optimal quantity pair that the agent demands $\left\{x_{i, k}\left(p_{1}^{*}, s_{i}\right), x_{i, l}\left(p_{2}^{*}, s_{i}\right)\right\}$. Put differently the system of FOCs specifies the best response of agent $i$ to all other agents choose $x_{m}\left(p_{m}, s_{j}\right)$, for the fixed profile of types $\left(s_{i}, s_{-i}\right)$.

To solve for a symmetric, linear ex-post equilibrium, I follow a guess and verify approach. It starts by making a guess about the form of the equilibrium strategy. I guess

$$
x_{m}\left(p_{m}, s_{i}\right)=a_{m} s_{i}-b_{m} p_{m}+c_{m} Q_{m}+e_{m} Q_{-m} \text { for } m=k, l, m \neq-m
$$

This guess implies that agent $i$ faces the following linear residual supply curves

$$
R S_{m}^{i}\left(p_{m}, s_{-i}\right)=Q_{m}\left[1-(n-1) c_{m}\right]-(n-1)\left\{e_{m} Q_{-m}-b_{m} p_{m}\right\}-a_{m} \sum_{j \neq i} s_{j}
$$

Now, the guessed strategy can only be a symmetric equilibrium if it is optimal for agent $i$ to choose this strategy $x_{m}\left(p_{m}, s_{i}\right)$ in responds to all others playing it. The goal is, therefore, to find the set of coefficients $\left\{a_{m}, b_{m}, c_{m}, e_{m}\right\}$ for $m=k, l$ such that this is the case. I do this in several steps. First, I find the best responses $\left\{x_{i, k}\left(p_{1}^{*}, s_{i}\right), x_{i, l}\left(p_{2}^{*}, s_{i}\right)\right\}$ of agent $i$, characterized system of FOCs when imposing that all others play the guess. Since preferences interlink both markets, each submitted demand $x_{i, m}\left(p_{m}^{*}, s_{i}\right)$ will depend how much the agent purchases or sells in the other auction $x_{i,-m}\left(p_{-m}^{*}, s_{i}\right)$. The second step is to determine how the winning quantity in the other market must be when all agents (including $i$ ) choose the guessed strategy. Substituting the winning quantity of the other market in the FOC, and rearranging, leaves us with the following system of equations

$$
\begin{aligned}
x_{i, k}\left(p_{1}^{*}, s_{i}\right) & =A_{1}\left(a_{2}, a_{1}, b_{1}\right) s_{i}-B_{1}\left(a_{2}, a_{1}, b_{1}\right) p_{1}^{*}+C_{1}\left(a_{2}, a_{1}, b_{1}, c_{1}\right) Q_{1}+E_{1}\left(a_{2}, a_{1}, b_{1}, e_{1}\right) Q_{2} \\
x_{i, l}\left(p_{2}^{*}, s_{i}\right) & =A_{2}\left(a_{1}, a_{2}, b_{2}\right) s_{i}-B_{2}\left(a_{1}, a_{2}, b_{2}\right) p_{2}^{*}+C_{2}\left(a_{1}, a_{2}, b_{2}, c_{2}\right) Q_{2}+E_{2}\left(a_{1}, a_{2}, b_{2}, e_{2}\right) Q_{1}
\end{aligned}
$$

where $A_{m}, B_{m}, C_{m}, C_{m}$ are functions of the coefficients of the guessed equilibrium strategy. In order for the guessed strategy to be the symmetric equilibrium it must be that agent $i$ chooses the same strategy as all others at all prices $p_{m}$ including the clearing price $p_{m}^{*}$. We therefore find an equilibrium candidate by matching the 'coefficients' of $i$ 's best response $A_{m}, B_{m}, C_{m}, C_{m}$ with the coefficients of the guessed strategy $a_{m}, b_{m}, c_{m}, e_{m}$. 
Step 1. To find the best responses $\left\{x_{i, k}\left(p_{1}^{*}, s_{i}\right), x_{i, l}\left(p_{2}^{*}, s_{i}\right)\right\}$ of agent $i$ to all others playing the guess, notice that the linear residual supply (19) implies two features. First

$$
\left(\frac{\partial R S_{m}^{i}\left(p_{m}, s_{-i}\right)}{\partial p_{m}}\right)=(n-1) b_{m}
$$

Second it establishes a one-to-one mapping between the sum of all other types $\sum_{j \neq i} s_{j}$ and a realized pair of residual supply curves. Intuitively, fixing a set of types that gives rise to a particular $\sum_{j \neq i} s_{j}$ is the same as fixing a pair of residual supply curves which only varies in this sum. Rearranging (19) we obtain

$$
\sum_{j \neq i} s_{j}=\frac{Q_{m}\left[1-(n-1) c_{m}\right]-(n-1)\left\{e_{m} Q_{-m}-b_{m} p_{m}\right\}-R S_{m}^{i}\left(p_{m}, s_{-i}\right)}{a_{m}}
$$

Naturally, (21) holds for $R S_{m}^{i}\left(p_{m}^{*}, s_{-i}\right)=x_{i, m}\left(p_{m}^{*}, s_{i}\right)$ at the optimal price. This brings us to the end of the first step. Inserting $(20)$ and $(21)$ at $p_{m}=p_{m}^{*}$ into the 17 s characterizes agent $i$ 's best responses $x_{i, m}\left(p_{m}^{*}, s_{i}\right)$ in both markets:

$$
0=-x_{i, m}\left(p_{m}^{*}, s_{i}\right)+\left(\gamma s_{i}+\kappa \sum_{j \neq i} s_{j}-p_{1}^{*}-\lambda x_{i, m}\left(p_{m}^{*}, s_{i}\right)-\delta x_{i,-m}\left(p_{-m}^{*}, s_{i}\right)\right)(n-1) b_{m}
$$

with

$$
\sum_{j \neq i} s_{j}=\frac{Q_{m}\left[1-(n-1) c_{m}\right]-(n-1)\left\{e_{m} Q_{-m}-b_{m} p_{m}^{*}\right\}-x_{i, m}\left(p_{m}^{*}, s_{i}\right)}{a_{m}}
$$

Step 2. As preferences interconnect both auctions, the quantity the agent demands at the clearing price in market $m, x_{i, m}\left(p_{m}^{*}, s_{i}\right)$, depends on how much the agent will win in the other market $-m, x_{i,-m}\left(p_{-m}^{*}, s_{i}\right)$. Now, because our guessed linear strategies can only be a symmetric equilibrium of it is optimal for agent $i$ to also choose this strategy, we know how much that will be. With all agents choosing the guess in market $-m$ it clears at

$$
p_{-m}^{*}=\left(\frac{1}{n}\right)\left(\frac{a_{-m}}{b_{-m}}\right) \sum_{i} s^{i}+\left(\frac{1}{b_{-m}}\right)\left[c_{-m}-\frac{1}{n}\right] Q_{-m}+\left(\frac{e_{-m}}{b_{-m}}\right) Q_{-m}
$$

Evaluating the guessed strategy at this price, we see that the agent must win the following in the other market

$$
x_{i,-m}\left(p_{-m}^{*}, s_{i}\right)=a_{-m}\left[\left(1-\frac{1}{n}\right) s_{i}-\frac{1}{n} \sum_{j \neq i} s_{j}\right]+\frac{1}{n} Q_{-m}
$$

We can thus substitute $x_{i,-m}\left(p_{-m}^{*}, s_{i}\right)$ out of $i$ 's characterization of his optimal choice in market $m$ $\left(\mathrm{BR}_{m}\right)$, using $(23)$. 
Step 3. This is convenient because it essentially leaves us with one equation that relates $x_{i, m}\left(p_{m}^{*}, s_{i}\right)$ with $p_{m}^{*}$ for $m=k, l$. Consider market $k$. Bringing $x_{i, k}\left(p_{1}^{*}, s_{i}\right)$ to the RHS of this equation reveals

$$
x_{i, k}\left(p_{1}^{*}, s_{i}\right)=A_{1}\left(a_{2}, a_{1}, b_{1}\right) s_{i}-B_{1}\left(a_{2}, a_{1}, b_{1}\right) p_{1}^{*}+C_{1}\left(a_{2}, a_{1}, b_{1}, c_{1}\right) Q_{1}+E_{1}\left(a_{2}, a_{1}, b_{1}, e_{1}\right) Q_{2}
$$

with

$$
\begin{aligned}
A_{1}\left(a_{2}, a_{1}, b_{1}\right) & =\frac{(n-1) b_{1}\left[\gamma-\delta(n-1) a_{2}\left(\frac{1}{n}\right)\right]}{\left[1+(n-1) b_{1}\left\{\frac{\kappa}{a_{1}}+\delta\left(\frac{a_{2}}{a_{1}}\right)\left(\frac{1}{n}\right)+\lambda\right\}\right]} \\
B_{1}\left(a_{2}, a_{1}, b_{1}\right) & =\frac{(n-1) b_{1}\left[1-\left((n-1) b_{1}\left\{\frac{\kappa}{a_{1}}+\delta\left(\frac{a_{2}}{a_{1}}\right)\left(\frac{1}{n}\right)\right\}\right)\right]}{\left[1+(n-1) b_{1}\left\{\frac{\kappa}{a_{1}}+\delta\left(\frac{a_{2}}{a_{1}}\right)\left(\frac{1}{n}\right)+\lambda\right\}\right]} \\
C_{1}\left(a_{2}, a_{1}, b_{1}, c_{1}\right)= & \frac{(n-1) b_{1}\left[\left\{\frac{\kappa}{a_{1}}+\delta\left(\frac{a_{2}}{a_{1}}\right)\left(\frac{1}{n}\right)\right\}\left[1-(n-1) c_{1}\right]\right]}{\left[1+(n-1) b_{1}\left\{\frac{\kappa}{a_{1}}+\delta\left(\frac{a_{2}}{a_{1}}\right)\left(\frac{1}{n}\right)+\lambda\right\}\right]} \\
E_{1}\left(a_{2}, a_{1}, b_{1}, e_{1}\right)= & \frac{-(n-1) b_{1}\left[\left\{\frac{\kappa}{a_{1}}+\delta\left(\frac{a_{2}}{a_{1}}\right)\left(\frac{1}{n}\right)\right\}(n-1) e_{1}+\delta \frac{1}{n}\right]}{\left[1+(n-1) b_{1}\left\{\frac{\kappa}{a_{1}}+\delta\left(\frac{a_{2}}{a_{1}}\right)\left(\frac{1}{n}\right)+\lambda\right\}\right]}
\end{aligned}
$$

An analogous equation holds for market $l$. For this to be the symmetric solution (i.e. an ex-post equilibrium) we must have that $i$ chooses the same strategy as all others, i.e.

$$
\begin{aligned}
& A_{1}\left(a_{2}, a_{1}, b_{1}\right)=a_{1}, B_{1}\left(a_{2}, a_{1}, b_{1}\right)=b_{1}, C_{1}\left(a_{2}, a_{1}, b_{1}, c_{1}\right)=c_{1}, E_{1}\left(a_{2}, a_{1}, b_{1}, e_{1}\right)=e_{1} . \\
& A_{2}\left(a_{1}, a_{2}, b_{2}\right)=a_{2}, B_{2}\left(a_{1}, a_{2}, b_{2}\right)=b_{2}, C_{2}\left(a_{1}, a_{2}, b_{2}, c_{2}\right)=c_{2}, E_{2}\left(a_{1}, a_{2}, b_{2}, e_{2}\right)=e_{2} .
\end{aligned}
$$

Solving this system of equations (see section 6.3.1) gives the following coefficients

$$
\begin{aligned}
a_{1}=a_{2}=b_{1} & =b_{2}=\left(\frac{n \gamma-2}{(\lambda+\delta)(n-1)}\right) \equiv b \\
c_{1} & =c_{2}=\kappa+\left(\frac{\delta}{n}\right) b \\
e_{1} & =e_{2}=-\left(\frac{\delta}{n}\right) b
\end{aligned}
$$

Inserting these coefficients into the guessed strategy gives the function of the theorem. It holds for $m=k, l, m \neq-m$.

$$
\begin{aligned}
& x_{m}\left(p_{m}, s_{i}\right)=b s_{i}-b p_{m}+\left(\kappa+\left(\frac{\delta}{n}\right) b\right) Q_{m}-\left(\frac{\delta}{n}\right) b Q_{-m} \\
& x_{m}\left(p_{m}, s_{i}\right)=b\left(s_{i}-p_{m}+\left(\frac{\delta}{n}\right)\left(Q_{m}-Q_{-m}\right)\right)+\kappa Q_{m} \\
& x_{m}\left(p_{m}, s_{i}\right)=\left(\frac{n \gamma-2}{(\lambda+\delta)(n-1)}\right)\left(s_{i}-p_{m}+\left(\frac{\delta}{n}\right)\left(Q_{m}-Q_{-m}\right)\right)+\kappa Q_{m}
\end{aligned}
$$


Or in terms of quantities

$$
b_{m}\left(q_{m}, s_{i}\right)=s_{i}-\left(\frac{n-1}{n-2}\right)\left\{(\lambda+\delta) q_{m}-\kappa Q_{m}\right\}+\left(\frac{\delta}{n}\right)\left(Q_{m}-Q_{-m}\right)
$$

By $(14)$

$$
b_{m}\left(q_{m}, s_{i}\right)=\bar{b}_{m}\left(q_{m}, q_{m} s_{i}\right)+\left(\frac{\delta}{n}\right)
$$

\subsection{Verifying that there is no profitable deviation}

To verify that the found strategy is indeed a maximum I verify the second order condition. The agent has no profitable deviation if

1. $\frac{\partial^{2} \pi\left(v_{i}, p_{1}^{*}, p_{2}^{*}\right)}{\partial^{2} p_{m}}<0$ for $m=k, l$

2. $\left|H\left(v_{i}, p_{1}^{*}, p_{2}^{*}\right)\right| \equiv\left|\begin{array}{ll}\frac{\partial^{2} \pi\left(v_{i}, p_{1}^{*}, p_{2}^{*}\right)}{\partial^{2} p_{1}} & \frac{\partial^{2} \pi\left(v_{i}, p_{1}^{*}, p_{2}^{*}\right)}{\partial p_{1} p_{2}} \\ \frac{\partial^{2} \pi\left(v_{i}, p_{1}^{*}, p_{2}^{*}\right)}{\partial p_{2} p_{1}} & \frac{\partial^{2} \pi\left(v_{i}, p_{1}^{*}, p_{2}^{*}\right)}{\partial^{2} p_{2}}\end{array}\right|>0$

Section 6.3.2 shows that the second order condition is fulfilled for any large number of agents iff $n \gamma>2$ and $|\delta| \leq \lambda$. Both holds by assumption.

\subsection{Algebraic derivations of the proof}

\subsubsection{Solving the system of FOCs}

I start by matching coefficients $A_{1}\left(a_{2}, a_{1}, b_{1}\right)=a_{1}$ and $B_{1}\left(a_{1}, a_{2}, b_{1}\right)=b_{1}$

$$
\begin{aligned}
a_{1}: a_{1}\left[1+(n-1) b_{1}\left\{\frac{\kappa}{a_{1}}+\delta\left(\frac{a_{2}}{a_{1}}\right)\left(\frac{1}{n}\right)+\lambda\right\}\right] & =(n-1) b_{1}\left[\gamma-\delta(n-1) a_{2}\left(\frac{1}{n}\right)\right] \\
\Rightarrow a_{1} & =\frac{(n-1) b_{1}\left[\gamma-\delta a_{2}-\kappa\right]}{1+(n-1) b_{1} \lambda}
\end{aligned}
$$

By symmetry of the problem

$$
\Rightarrow a_{2}=\frac{(n-1) b_{2}\left[\gamma-\delta a_{1}-\kappa\right]}{1+(n-1) b_{2} \lambda}
$$

If $a_{2}=a_{1} \equiv a, b_{2}=b_{1} \equiv b$

$$
\begin{aligned}
a & =\frac{(n-1) b(\gamma-\kappa)}{1+(n-1) b(\lambda+\delta)} \\
b_{1}: \quad b_{1}\left[1+(n-1) b_{1}\left\{\frac{\kappa}{a_{1}}+\delta\left(\frac{a_{2}}{a_{1}}\right)\left(\frac{1}{n}\right)+\lambda\right\}\right] & =(n-1) b_{1}\left[1-\left((n-1) b_{1}\left\{\frac{\kappa}{a_{1}}+\delta\left(\frac{a_{2}}{a_{1}}\right)\left(\frac{1}{n}\right)\right\}\right)\right] \\
\Rightarrow b_{1} & =\frac{n-2}{(n-1)\left\{\left[\left(\frac{\kappa}{a_{1}}\right) n+\delta\left(\frac{a_{2}}{a_{1}}\right)\right]+\lambda\right\}}
\end{aligned}
$$


By symmetry of the problem

$$
\Rightarrow b_{2}=\frac{n-2}{(n-1)\left\{\left[\left(\frac{\kappa}{a_{2}}\right) n+\delta\left(\frac{a_{1}}{a_{2}}\right)\right]+\lambda\right\}}
$$

If $a_{2}=a_{1}=a$, then

$$
b_{1}=b_{2}=b=\frac{n-2}{(n-1)\left\{\left[\left(\frac{\kappa}{a}\right) n+\delta\right]+\lambda\right\}}
$$

Now I solve for $a_{1}, b_{1}$ by inserting (28) into (25) and (29) into (26) to obtain expressions $a_{1}\left(a_{2}\right), a_{2}\left(a_{1}\right)$, which I can solve for $a_{1}, a_{2}$ by $a_{1}\left(a_{2}\right)=a_{1}$ and $a_{2}\left(a_{1}\right)=a_{2}$.

Start by inserting (28) into (25)

$$
a_{1}=\frac{(n-1)\left(\frac{n-2}{(n-1)\left\{\left[\left(\frac{\kappa}{a_{1}}\right) n+\delta\left(\frac{a_{2}}{a_{1}}\right)\right]+\lambda\right\}}\right)\left[\gamma-\delta a_{2}-\kappa\right]}{1+(n-1)\left(\frac{n-2}{(n-1)\left\{\left[\left(\frac{\kappa}{a_{1}}\right) n+\delta\left(\frac{a_{2}}{a_{1}}\right)\right]+\lambda\right\}}\right) \lambda}
$$

and rearranging

$$
\begin{aligned}
a_{1}\left\{(n-1)\left\{\left[\left(\frac{\kappa}{a_{1}}\right) n+\delta\left(\frac{a_{2}}{a_{1}}\right)\right]+\lambda\right\}+(n-1)(n-2) \lambda\right\} & =(n-1)(n-2)\left(\gamma-\delta a_{2}-\kappa\right) \\
(n-1) n \kappa+(n-1) \delta a_{2}+a_{1}(n-1) \lambda+a_{1}(n-1)(n-2) \lambda & =(n-1)(n-2)\left(\gamma-\delta a_{2}-\kappa\right) \\
(n-2) \gamma-2(n-1) \kappa & =(n-1)\left\{\delta a_{2}+\lambda a_{1}\right\}
\end{aligned}
$$

By symmetry we obtain the analogous expression when inserting $b_{2}\left(a_{1}, a_{2}\right)$ into $a_{2}\left(b_{2}, a_{1}\right)$

$$
(n-2) \gamma-2(n-1) \kappa=(n-1)\left\{\delta a_{1}+\lambda a_{2}\right\}
$$

Subtracting (32) from (31)

$$
\Rightarrow 0=(n-1)\left\{\delta a_{2}+\lambda a_{1}\right\}-(n-1)\left\{\delta a_{1}+\lambda a_{2}\right\}
$$

It follows that

$$
\Rightarrow a_{2}=a_{1} \equiv a
$$

With $a_{2}=a_{1}=a$, we must have $b_{2}=b_{1}=b$

$$
\Rightarrow b_{2}=b_{1} \equiv b
$$

Having shown that coefficients are the same in both markets, we can solve $a(b), b(a)$ by inserting (27) into (30) and solving for $b$

$$
\begin{aligned}
b(n-1)\left\{\left[\frac{n \kappa[1+(n-1) b(\lambda+\delta)]}{b(n-1)(\gamma-\kappa)}+\delta\right]+\lambda\right\} & =n-2 \\
n \kappa[1+(n-1) b(\lambda+\delta)]+b(n-1)(\delta+\lambda)(\gamma-\kappa) & =(n-2)(\gamma-\kappa) \\
\Rightarrow b & =\frac{(n-2) \gamma-(n-1) \kappa}{(n-1)(\lambda+\delta)(\gamma+(n-1) \kappa)}
\end{aligned}
$$


With normalization $\gamma+(n-1) \kappa=1$ we have

$$
\Rightarrow b=\frac{n \gamma-2}{(n-1)(\lambda+\delta)}
$$

We back out $a$ by plugging $b$ into $a(b)$ as given in (27):

$$
\Rightarrow a=\frac{(n \gamma-2)(\gamma-\kappa)}{(\lambda+\delta)(n \gamma-1)}
$$

Using the normalization we can show that this is the same as $b$

$$
\Rightarrow a=b
$$

Having determined $a, b$ it is straightforward to solve $C_{1}\left(a, b, c_{1}\right)=c_{1}$ and $E_{1}\left(a, b, e_{1}\right)=e_{1}$.

$c_{1}: \quad c_{1}\left[1+(n-1) b_{1}\left\{\frac{\kappa}{a_{1}}+\delta\left(\frac{a_{2}}{a_{1}}\right)\left(\frac{1}{n}\right)+\lambda\right\}\right]=(n-1) b_{1}\left[\left\{\frac{\kappa}{a_{1}}+\delta\left(\frac{a_{2}}{a_{1}}\right)\left(\frac{1}{n}\right)\right\}\left[1-(n-1) c_{1}\right]\right]$

In symmetric solution with $a_{1}=a_{2}=a, b_{1}=b_{2}=b$

$$
\begin{aligned}
\Rightarrow c_{1}\left[1+n(n-1)\left[\kappa+b \delta \frac{1}{n}\right]+(n-1) b \lambda\right] & =(n-1)\left[\kappa+b \delta \frac{1}{n}\right] \\
\Rightarrow c_{1} & =\kappa+\frac{\delta}{n} b=\kappa+\frac{\delta}{n}\left[\frac{n \gamma-2}{(n-1)(\lambda+\delta)}\right]
\end{aligned}
$$

and

$e_{1}: e_{1}\left[1+(n-1) b_{1}\left\{\frac{\kappa}{a_{1}}+\delta\left(\frac{a_{2}}{a_{1}}\right)\left(\frac{1}{n}\right)+\lambda\right\}\right]=-(n-1) b_{1}\left[\left\{\frac{\kappa}{a_{1}}+\delta\left(\frac{a_{2}}{a_{1}}\right)\left(\frac{1}{n}\right)\right\}(n-1) e_{1}+\delta \frac{1}{n}\right]$

In symmetric solution with $a_{1}=a_{2}=a, b_{1}=b_{2}=b$

$$
\begin{aligned}
e_{1}\left[1+(n-1) b\left\{\frac{\kappa}{b}+\delta\left(\frac{1}{n}\right)+\lambda\right\}\right] & =-(n-1) b\left[\left\{\frac{\kappa}{b}+\delta\left(\frac{1}{n}\right)\right\}(n-1) e_{1}+\delta \frac{1}{n}\right] \\
\Rightarrow e_{1} & =-\frac{\delta}{n} b=-\frac{\delta}{n}\left[\frac{n \gamma-2}{(n-1)(\lambda+\delta)}\right]
\end{aligned}
$$

\subsubsection{Verifying the SOC}

The second derivative in market $k$ is

$$
\frac{\partial^{2} \pi\left(v_{i}, p_{1}, p_{2}\right)}{\partial^{2} p_{1}}=-\left(\frac{\partial R S_{k}^{i}\left(p_{1}, s_{-i}\right)}{\partial p_{1}}\right)+\left(-1-\lambda \frac{\partial R S_{k}^{i}\left(p_{1}, s_{-i}\right)}{\partial p_{1}}\right)\left(\frac{\partial R S_{k}^{i}\left(p_{1}, s_{-i}\right)}{\partial p_{1}}\right)
$$


At the solution

$$
\begin{aligned}
\frac{\partial^{2} \pi\left(v_{i}, p_{1}^{*}, p_{2}^{*}\right)}{\partial^{2} p_{1}} & =-(n-1) b+(-1-\lambda(n-1) b)(n-1) b \\
& =-(n-1) b\{1+[1+\lambda(n-1) b]\} \\
& =-(n-1) b[2+\lambda(n-1) b] \\
& =-\left(\frac{n \gamma-2}{\lambda+\delta}\right)\left[2+\lambda\left(\frac{n \gamma-2}{\lambda+\delta}\right)\right] \\
& =-\left(\frac{n \gamma-2}{\lambda+\delta}\right)\left(\frac{2 \delta+\lambda n \gamma}{\lambda+\delta}\right) \\
& <0 \text { holds since } n \gamma>2 \text { and }|\delta| \leq \lambda
\end{aligned}
$$

The cross-partial derivative is

$$
\frac{\partial^{2} \pi\left(v_{i}, p_{1}^{*}, p_{2}^{*}\right)}{\partial p_{1} p_{2}}=-\delta\left(\frac{\partial R S_{k}^{i}\left(p_{1}, s_{-i}\right)}{\partial p_{1}}\right)\left(\frac{\partial R S_{l}^{i}\left(p_{2}, s_{-i}\right)}{\partial p_{2}}\right)
$$

At the solution

$$
\frac{\partial^{2} \pi\left(v_{i}, p_{1}^{*}, p_{2}^{*}\right)}{\partial p_{1} p_{2}}=-\delta(n-1)^{2} b^{2}
$$

By symmetry of the problem, the hessian therefore is

$$
H\left(v_{i}, p_{1}^{*}, p_{2}^{*}\right)=\left|\begin{array}{cc}
-(n-1) b[2+\lambda(n-1) b] & -\delta(n-1)^{2} b^{2} \\
-\delta(n-1)^{2} b^{2} & -(n-1) b[2+\lambda(n-1) b]
\end{array}\right|
$$

The determinant of the hessian matrix is

$$
\operatorname{Det}\left(H\left(v_{i}, p_{1}^{*}, p_{2}^{*}\right)\right)>0 \Leftrightarrow\{(n-1) b[2+\lambda(n-1) b]\}^{2}-\delta^{2}(n-1)^{4} b^{4}>0
$$

Since $(n-1) b>0$

$$
\Leftrightarrow[2+\lambda(n-1) b]^{2}>\delta^{2}(n-1)^{2} b^{2}
$$

Taking the square root

$$
\begin{aligned}
& \Leftrightarrow[2+\lambda(n-1) b]>\delta(n-1) b \\
& \Leftrightarrow 2>(\delta-\lambda)(n-1) b
\end{aligned}
$$

At the solution

$$
\Leftrightarrow 2>\left(\frac{\delta-\lambda}{\lambda+\delta}\right)(n \gamma-2)
$$

We know $n \gamma>2$ (since $n>2$ ). Then this condition holds independent of how many agents there are as long as $|\delta| \geq \lambda$. 


\section{Proof of Lemma 3}

The proof involves in two main steps. First I derive the first-order condition that characterizes the BNE of two simultaneous uniform-price double auctions for a broad class of utility functions and any distributions with differentiable CDF (section 7.1). Then I assume that all random variables are normally distributed and derive the functional form that a BNE must admit (section 7.2).

\subsection{General optimality condition}

Let $\boldsymbol{s}_{\boldsymbol{i}}$ (iid) and $\left\{\boldsymbol{Q}_{\mathbf{1}}, Q_{\mathbf{2}}\right\}$ be drawn from distributions with differentiable distribution functions. The proof is written for the case in which at least one of the random variables has an unbounded support (as with the normal distribution). Bounded support can be handled accordingly.

Fix some type $s_{i}$ and let $U\left(q_{1}, q_{2}, s_{1}\right)$ be continuous, twice differentiable, with continuous partial and cross-partial derivatives. Denote

$$
\begin{aligned}
\mu_{m}\left(q_{m}, q_{-m}, s_{i}\right) & \equiv \frac{\partial U\left(q_{1}, q_{2}, s_{i}\right)}{\partial q_{m}} \\
\mu\left(q_{1}, q_{2}, s_{i}\right) & \equiv \frac{\partial^{2} U\left(q_{1}, q_{2}, s_{i}\right)}{\partial q_{1} \partial q_{2}}=\frac{\partial^{2} U\left(q_{1}, q_{2}, s_{i}\right)}{\partial q_{2} \partial q_{1}} \quad \text { (by Schwarz's Theorem) }
\end{aligned}
$$

Recall that $i$ 's equilibrium winning quantity in auction $m \boldsymbol{q}_{\boldsymbol{i}, \boldsymbol{m}}^{*}$ and the clearing price by $\boldsymbol{p}_{\boldsymbol{m}}^{*}$ are for $m=1,2$ implicitly defined by market clearing

$$
\boldsymbol{q}_{\boldsymbol{i}, \boldsymbol{m}}^{*}=\boldsymbol{Q}_{\boldsymbol{m}}-\sum_{j \neq i} x_{m}\left(\boldsymbol{p}_{\boldsymbol{m}}^{\boldsymbol{*}}, \boldsymbol{s}_{\boldsymbol{j}}\right) \text { with } \boldsymbol{p}_{\boldsymbol{m}}^{*}=b_{m}\left(\boldsymbol{q}_{\boldsymbol{i}, \boldsymbol{m}}^{\boldsymbol{m}}, s_{i}\right)
$$

and that I denote the residual supply curve in $m$ by

$$
R S_{m}\left(p_{m}, s_{-i}, Q_{m}\right)=Q_{m}-\sum_{j \neq i} x_{j, m}\left(p_{m}, s_{j}\right)
$$

Definition 3. Define the joint distribution over $i$ 's clearing price quantities as the probability that agent $i$ receives at most quantity $q_{1}$ and at most quantity $q_{2}$ when bidding $b_{i, 1}\left(q_{1}, s_{i}\right), b_{i, 2}\left(q_{2}, s_{i}\right)$ as

$$
G^{i}\left(q_{1}, q_{2}, b_{i, 1}\left(q_{1}, s_{i}\right), b_{i, l}\left(q_{2}, s_{i}\right)\right) \equiv \operatorname{Pr}\left(\boldsymbol{q}_{\boldsymbol{i}, \mathbf{1}}^{\boldsymbol{*}} \leq q_{1} \text { and } \boldsymbol{q}_{\boldsymbol{i}, \mathbf{2}}^{\boldsymbol{*}} \leq q_{2}\right)
$$

Analogously, define the marginal distribution of $i$ 's clearing price quantity in market $m=1,2$ by

$$
\left.G_{m}^{i}\left(q_{m}, b_{i, m}\left(q_{m}, s_{i}\right)\right)=\operatorname{Pr}\left(\boldsymbol{q}_{\boldsymbol{i}, \boldsymbol{m}}^{\boldsymbol{*}} \leq q_{m}\right)\right)
$$

And the conditional distribution

$$
G_{2 \mid 1}^{i}\left(q_{2}, b_{i, 2}\left(q_{2}, s_{i}\right) \mid q_{1}, b_{i, 1}\left(q_{1}, s_{i}\right)=\operatorname{Pr}\left(\boldsymbol{q}_{\boldsymbol{i}, \mathbf{2}}^{\boldsymbol{*}} \leq q_{2} \mid \boldsymbol{q}_{\boldsymbol{i} \mathbf{i}}^{\boldsymbol{*}} \leq q_{1}\right) .\right.
$$

I denote the corresponding joint and marginal density functions by $g^{i}, g_{m}^{i}$ and $g_{2 \mid 1}^{i}$, and oftentimes abbreviate $b_{i, m}\left(q_{m}, s_{i}\right)=b_{i, m}$ for notational convenience. 
Take the perspective of agent $i$. Fix his type $s_{i}$, and denote his objective function by

$$
\mathcal{V}\left(b_{i, 1}\left(\cdot, s_{i}\right), b_{i, 2}\left(\cdot, s_{i}\right)\right)=\mathbb{E}\left[U\left(\boldsymbol{q}_{\boldsymbol{i}, \mathbf{1}}^{\boldsymbol{*}}, \boldsymbol{q}_{\boldsymbol{i}, \mathbf{2}}^{\boldsymbol{*}}, s_{i}\right)-\sum_{m=1,2} \boldsymbol{q}_{\boldsymbol{i}, \boldsymbol{m}}^{\boldsymbol{*}} \boldsymbol{p}_{\boldsymbol{m}}^{\boldsymbol{*}}\right]
$$

Fix the strategies of all other agents at the equilibrium strategy $\left\{b_{1}^{*}\left(\cdot, s_{j}\right), b_{2}^{*}\left(\cdot, s_{j}\right)\right\} \forall j \neq i$. It consists of two differentiable and weakly decreasing bidding functions. By definition of a symmetric equilibrium there cannot be another pair of functions different from $\left\{b_{1}^{*}\left(\cdot, s_{i}\right), b_{2}^{*}\left(\cdot, s_{i}\right)\right\}$ which generates a higher payoff for agent $i$ :

$$
\left\{b_{1}^{*}\left(\cdot, s_{i}\right), b_{2}^{*}\left(\cdot, s_{i}\right)\right\}=\arg \max _{b_{i, 1}\left(\cdot, s_{i}\right), b_{i, 2}\left(\cdot, s_{i}\right)} \mathcal{V}\left(b_{i, 1}\left(\cdot, s_{i}\right), b_{i, 2}\left(\cdot, s_{i}\right)\right)
$$

Since $\left\{b_{1}^{*}\left(\cdot, s_{i}\right), b_{2}^{*}\left(\cdot, s_{i}\right)\right\}$ must be the solution to $i$ 's maximization problem each function must solve the agent's maximization problem holding fixed the other:

$$
\Rightarrow b_{m}^{*}\left(\cdot, s_{i}\right)=\arg \max _{b_{i, m}\left(\cdot, s_{i}\right)} \mathcal{O}\left(b_{i, m}\left(\cdot, s_{i}\right)\right) \text { with } \mathcal{O}\left(b_{i, m}\left(\cdot, s_{i}\right)\right) \equiv \mathcal{V}\left(b_{i, m}\left(\cdot, s_{i}\right), b_{-m}^{*}\left(\cdot, s_{i}\right)\right)
$$

for $m=1$ or 2 and $m \neq-m$. Otherwise there would be another pair of functions that would generate a higher payoff for the agent, so that $\left\{b_{1}^{*}\left(\cdot, s_{i}\right), b_{2}^{*}\left(\cdot, s_{i}\right)\right\}$ could not be the solution of the joint maximization problem $(J M)$.

Auxiliary Lemma 1. Denote $\dot{b}_{i, m}\left(q_{m}, s_{i}\right)=\frac{\partial b_{i, m}\left(q_{m}, s_{i}\right)}{\partial q_{m}}$.

$$
\mathcal{O}\left(b_{i, m}\left(\cdot, s_{i}\right)\right)=\int_{-\infty}^{\infty} \mathcal{F}\left(q_{m}, b_{i, m}\left(q_{m}, s_{i}\right), \dot{b}_{i, m}\left(q_{m}, s_{i}\right)\right) d q_{m}+\text { const }
$$

and $\mathcal{F}(\cdot, \cdot, \cdot)$ is continuous in its three arguments and has continuous partial derivatives with respect to the second and third.

[Proof to be added]

Since $\mathcal{O}\left(b_{i, m}\left(\cdot, s_{i}\right)\right)$ is additive separable, $b_{m}^{*}\left(\cdot, s_{i}\right)$ can only maximize $\mathcal{O}\left(b_{i, m}\left(\cdot, s_{i}\right)\right)$ if for each $q_{m}$ the bid value $b_{m}^{*}\left(q_{m}, s_{i}\right)$ maximizes $\mathcal{F}\left(q_{m}, b_{i, m}\left(q_{m}, s_{i}\right), \dot{b}_{i, m}\left(q_{m}, s_{i}\right)\right)$. The following lemma characterizes this bid value for each $q_{m}$.

Auxiliary Lemma 2. (i) If $b_{m}\left(q_{m}, s_{i}\right)$ maximizes $\mathcal{F}\left(q_{m}, b_{i, m}\left(q_{m}, s_{i}\right), \dot{b}_{i, m}\left(q_{m}, s_{i}\right)\right)$ then

$$
\mathbb{E}\left[\frac{\partial U\left(q_{m}, \boldsymbol{q}_{\boldsymbol{i},-\boldsymbol{m}}^{*}, s_{i}\right)}{\partial q_{m}} \mid q_{m}\right]-b_{m}\left(q_{m}, s_{i}\right)=-q_{m}\left[\frac{\frac{\partial G_{m}^{i}\left(q_{m}, b_{m}\left(q_{m}, s_{i}\right)\right)}{\partial q_{m}}}{\frac{\partial G_{m}^{i}\left(q_{m}, b_{m}\left(q_{m}, s_{i}\right)\right)}{\partial b_{i, m}\left(q_{m}, s_{i}\right)}}\right]
$$

(ii) When $b^{-1}\left(\cdot, s_{i}\right)=x_{m}\left(\cdot, s_{i}\right)$ is additive separable in $s_{i}$

$$
\mathbb{E}\left[\frac{\partial U\left(q_{m}, \boldsymbol{q}_{\boldsymbol{i},-\boldsymbol{m}}^{*}, s_{i}\right)}{\partial q_{m}} \mid q_{m}\right]-b_{m}\left(q_{m}, s_{i}\right)=q_{m}\left(\frac{\partial R S_{m}\left(b_{m}\left(q_{m}, s_{i}\right), s_{-i}, Q_{m}\right)}{\partial b_{i, m}\left(q_{m}, s_{i}\right)}\right)^{-1}
$$

[Proof to be added]

When $b_{m}^{*}\left(\cdot, s_{i}\right)$ is part of the BNE strategy it thus must be that condition (42) holds for all $q_{m}$. It is the first-order condition of the BNE function in auction $m$. 


\subsection{Functional form of the BNE}

I will follow a guess and verify strategy, guessing that the equilibrium will take the following form

$$
b_{m}^{B N E}\left(q_{m}, s_{i}\right)=\epsilon_{m}+\alpha_{m} s_{i}-\beta_{m} q_{m}
$$

Under the linear guess and with the quadratic utility function, FOC (43) reads

$$
s_{i}-\lambda q_{m}-\delta \mathbb{E}\left[\boldsymbol{q}_{\boldsymbol{i},-\boldsymbol{m}}^{*} \mid q_{m}\right]-b_{m}\left(s^{i}, q_{m}\right)=\left[\frac{q_{m}}{(n-1) \frac{1}{\beta_{m}}}\right]
$$

Once I have determined an expression for the conditional expectation, I find the equilibrium strategies by matching coefficients of agent $i$ 's best reply functions to the guess. Only if $i$ chooses the same strategy as all other agents we have found a symmetric equilibrium. Below, in section 7.2.1, I show that under the assumed normal distributions

$$
\begin{aligned}
\mathbb{E}\left[\boldsymbol{q}_{\boldsymbol{i},-\boldsymbol{m}}^{*} \mid q_{m}\right] & =\left(\frac{1}{n}\right)\left[\left[\mu_{-m}-\alpha_{-m}(n-1) \mu_{s}\right]-\left(\frac{\alpha_{m} \alpha_{-m}(n-1) \sigma_{s}^{2}+\rho \sigma^{2}}{\alpha_{m}^{2}(n-1) \sigma_{s}^{2}+\sigma^{2}}\right)\left[\mu_{m}-\alpha_{1}(n-1) \mu_{s}\right]\right] \\
& +\left(\frac{1}{n}\right)(n-1)\left[\alpha_{-m}-\left(\frac{\alpha_{m} \alpha_{-m}(n-1) \sigma_{s}^{2}+\rho \sigma^{2}}{\alpha_{m}^{2}(n-1) \sigma_{s}^{2}+\sigma^{2}}\right) \alpha_{m}\right] s_{i} \\
& +\left(\frac{\alpha_{m} \alpha_{-m}(n-1) \sigma_{s}^{2}+\rho \sigma^{2}}{\alpha_{m}^{2}(n-1) \sigma_{s}^{2}+\sigma^{2}}\right) q_{m}
\end{aligned}
$$

Inserting into (44) into the FOC and rearranging gives

$$
\begin{aligned}
b_{m}\left(s_{i}, q_{m}\right) & =E_{m}\left(\alpha_{m}, \alpha_{-m}\right)+A_{m}\left(\alpha_{m}, \alpha_{-m}\right) s_{i}-B_{m}\left(\alpha_{m}, \alpha_{-m}, \beta_{m}\right) q_{m} \text { with } \\
E_{m}\left(\alpha_{m}, \alpha_{-m}\right) & =-\delta\left(\frac{1}{n}\right)\left[\left[\mu_{-m}-\alpha_{-m}(n-1) \mu_{s}\right]-\left(\frac{\alpha_{m} \alpha_{-m}(n-1) \sigma_{s}^{2}+\rho \sigma^{2}}{\alpha_{m}^{2}(n-1) \sigma_{s}^{2}+\sigma^{2}}\right)\left[\mu_{m}-\alpha_{1}(n-1) \mu_{s}\right]\right] \\
A_{m}\left(\alpha_{m}, \alpha_{-m}\right) & =1-\delta\left(\frac{1}{n}\right)(n-1)\left[\alpha_{-m}-\left(\frac{\alpha_{m} \alpha_{-m}(n-1) \sigma_{s}^{2}+\rho \sigma^{2}}{\alpha_{m}^{2}(n-1) \sigma_{s}^{2}+\sigma^{2}}\right) \alpha_{m}\right] \\
B_{m}\left(\alpha_{m}, \alpha_{-m}, \beta_{m}\right) & =\left[\frac{(n-1) \frac{1}{\beta_{m}} \lambda+1}{(n-1) \frac{1}{\beta_{m}}}\right]+\delta\left(\frac{\alpha_{m} \alpha_{-m}(n-1) \sigma_{s}^{2}+\rho \sigma^{2}}{\alpha_{m}^{2}(n-1) \sigma_{s}^{2}+\sigma^{2}}\right)
\end{aligned}
$$

In the symmetric equilibrium we must have

$$
\begin{aligned}
E_{m}\left(\alpha_{m}, \alpha_{-m}\right) & =\epsilon_{m} \\
A_{m}\left(\alpha_{m}, \alpha_{-m}\right) & =\alpha_{m} \\
B_{m}\left(\alpha_{m}, \alpha_{-m}, \beta_{m}\right) & =\beta_{m}
\end{aligned}
$$

for both markets. It can be shown that the solution must be symmetric. Here I use a short-cut and simply impose symmetry. Denote the correlation of the winning quantities as

$$
\rho^{i}(\alpha) \equiv \frac{\alpha^{2}(n-1) \sigma_{s}^{2}+\rho \sigma^{2}}{\alpha^{2}(n-1) \sigma_{s}^{2}+\sigma^{2}}
$$


The equilibrium parameter then must solve

$$
\begin{aligned}
\epsilon & =-\delta\left(\frac{1}{n}\right)\left[\left[\mu_{-m}-\alpha(n-1) \mu_{s}\right]-\rho^{i}(\alpha)\left[\mu_{m}-\alpha(n-1) \mu_{s}\right]\right] \\
\alpha & =1-\delta\left(\frac{1}{n}\right)(n-1) \alpha\left[1-\rho^{i}(\alpha)\right] \\
\beta & =\left[\frac{(n-1) \frac{1}{\beta} \lambda+1}{(n-1) \frac{1}{\beta}}\right]+\delta \rho^{i}(\alpha)
\end{aligned}
$$

From the last equation can express $\beta$ in terms of $\alpha$

$$
\beta=\left(\frac{n-1}{n-2}\right)\left(\lambda+\delta \rho^{i}(\alpha)\right)
$$

The equilibrium therefore must take the functional form as stated in the lemma

$$
\begin{aligned}
b_{m}^{B N E}\left(q_{m}, s_{i}\right)=\epsilon(\alpha)+\alpha s_{i}-\beta(\alpha) p_{m} \text { with } \alpha & =1-\delta \alpha\left(\frac{1}{n}\right)(n-1)\left[1-\rho^{i}(\alpha)\right] \\
\beta(\alpha) & =\left(\frac{n-1}{n-2}\right)\left(\lambda+\delta \rho^{i}(\alpha)\right) \\
\epsilon(\alpha) & =\delta\left(\frac{1}{n}\right)\left[\left[\rho^{i}(\alpha) \mu_{m}-\mu_{-m}\right]+\alpha(n-1) \mu_{s}\left[1-\rho^{i}(\alpha)\right]\right]
\end{aligned}
$$

\subsubsection{Algebraic derivation of the conditional expectation}

I derive the conditional expectation in three steps. First I the joint distribution of $X_{m}^{i} \equiv Q_{m}-$ $\alpha_{m} \sum_{j \neq i} \boldsymbol{s}_{\boldsymbol{j}}$ for $m=1,2$. Then the one of $\boldsymbol{q}_{\boldsymbol{i}, \boldsymbol{m}}^{\boldsymbol{*}}=\frac{1}{n}\left[\boldsymbol{X}_{\boldsymbol{m}}^{\boldsymbol{i}}+(n-1) \alpha_{m} s_{i}\right]$. Finally, I determine the conditional expectation. ${ }^{9}$

Step 1. Let us start with determining the joint distribution of $\left\{\boldsymbol{X}_{\mathbf{1}}^{\boldsymbol{i}}, \boldsymbol{X}_{\mathbf{2}}^{\boldsymbol{i}}\right\}$. These random variables are linear combinations of normally distributed variables and are therefore jointly normally distributed. ${ }^{9}$ We can write

$$
\left(\begin{array}{c}
X_{1}^{i} \\
X_{2}^{i}
\end{array}\right)=A_{2 \times 3} Y_{3 \times 1} \quad \text { with } \boldsymbol{A}_{2 \times 3} \equiv\left(\begin{array}{ccc}
-\alpha_{1} & 1 & 0 \\
-\alpha_{2} & 0 & 1
\end{array}\right) \quad \text { and } \quad \boldsymbol{Y}_{3 \times 1} \equiv\left(\begin{array}{c}
\sum_{j \neq i} s_{j} \\
Q_{1} \\
Q_{2}
\end{array}\right)
$$

For normal distributions we know ${ }^{9}$

$$
\left(\begin{array}{c}
X_{1}^{i} \\
X_{2}^{i}
\end{array}\right)=\boldsymbol{A}_{2 \times 3} Y_{3 \times 1} \sim N_{q}\left(\boldsymbol{A} \boldsymbol{\mu}, \boldsymbol{A} \Sigma \boldsymbol{A}^{\prime}\right) \equiv N\left(\mu_{X}, \Sigma_{X}\right)
$$

$\mu_{X}=\left(\begin{array}{lll}-\alpha_{1} & 1 & 0 \\ -\alpha_{2} & 0 & 1\end{array}\right)\left(\begin{array}{c}(n-1) \mu_{s} \\ \mu_{1} \\ \mu_{2}\end{array}\right)=\left(\begin{array}{l}-\alpha_{1}(n-1) \mu_{s}+\mu_{1} \\ -\alpha_{2}(n-1) \mu_{s}+\mu_{2}\end{array}\right)$

and

$\Sigma_{X}=\left(\begin{array}{ccc}-\alpha_{1} & 1 & 0 \\ -\alpha_{2} & 0 & 1\end{array}\right)\left(\begin{array}{ccc}(n-1) \sigma_{s}^{2} & 0 & 0 \\ 0 & \sigma^{2} & \rho \sigma \sigma \\ 0 & \rho \sigma \sigma & \sigma^{2}\end{array}\right)\left(\begin{array}{cc}-\alpha_{1} & -\alpha_{2} \\ 1 & 0 \\ 0 & 1\end{array}\right)=\left(\begin{array}{cc}\alpha_{1}^{2}(n-1) \sigma_{s}^{2}+\sigma^{2} & \alpha_{1} \alpha_{2}(n-1) \sigma_{s}^{2}+\rho \sigma^{2} \\ \alpha_{1} \alpha_{2}(n-1) \sigma_{s}^{2}+\rho \sigma^{2} & \alpha_{2}^{2}(n-1) \sigma_{s}^{2}+\sigma^{2}\end{array}\right)$

\footnotetext{
${ }^{9}$ In deriving the conditional expectation I rely on the following lemma:
} 
Step 2. In the linear equilibrium, the winning quantities are linear transformations of $\left\{\boldsymbol{X}_{\mathbf{1}}^{\boldsymbol{i}}, \boldsymbol{X}_{\mathbf{2}}^{\boldsymbol{i}}\right\}$.

$$
\left(\begin{array}{c}
\boldsymbol{q}_{\boldsymbol{i}, \mathbf{1}}^{*} \\
\boldsymbol{q}_{\boldsymbol{i}, \mathbf{2}}^{*}
\end{array}\right)=\boldsymbol{a}_{2 \times 1}^{\prime} \boldsymbol{X}_{2 \times 1}+\boldsymbol{d}_{2 \times 1} \text { with } \boldsymbol{X}_{2 \times 1} \equiv\left(\begin{array}{c}
X_{1}^{i} \\
X_{2}^{i}
\end{array}\right) \text { and } \boldsymbol{a}_{2 \times 1} \equiv\left(\frac{1}{n}\right)\left(\begin{array}{l}
1 \\
1
\end{array}\right) \text { and } \boldsymbol{d}_{2 \times 1} \equiv\left(\frac{1}{n}\right)\left(\begin{array}{c}
(n-1) \alpha_{1} s_{i} \\
(n-1) \alpha_{2} s_{i}
\end{array}\right)
$$

Since all all random variables are jointly normal distributed, we know ${ }^{9}$

$$
\left(\begin{array}{l}
q_{1}^{i} \\
q_{2}^{i}
\end{array}\right) \sim N\left(\boldsymbol{a}_{2 \times 1}^{\prime} \mu_{x}+\boldsymbol{d}_{2 \times 1}, \boldsymbol{a}_{2 \times 1} \Sigma_{X} \boldsymbol{a}_{2 \times 1}^{\prime}\right)
$$

with

$$
\boldsymbol{a}_{2 \times 1}^{\prime} \boldsymbol{X}_{2 \times 1}+\boldsymbol{d}_{2 \times 1}=\left(\frac{1}{n}\right) \mu_{x}+\left(\frac{1}{n}\right)\left(\begin{array}{c}
(n-1) \alpha_{1} s_{i} \\
(n-1) \alpha_{2} s_{i}
\end{array}\right) \quad \text { and } \quad \boldsymbol{a}_{2 \times 1} \Sigma_{X} \boldsymbol{a}_{2 \times 1}^{\prime}=\left(\frac{1}{n}\right)^{2} \Sigma_{X}
$$

So that

$$
\left(\begin{array}{l}
q_{1}^{i} \\
q_{2}^{i}
\end{array}\right) \sim N\left(\left(\begin{array}{c}
\mu_{q_{1}^{i}} \\
\mu_{q_{2}^{i}}
\end{array}\right),\left(\begin{array}{cc}
\sigma_{q_{1}^{i}}^{2} & \rho^{i} \sigma_{q_{1}^{i}} \sigma_{q_{2}^{i}} \\
\rho^{i} \sigma_{q_{1}^{i}} \sigma_{q_{2}^{i}} & \sigma_{q_{2}^{i}}^{2}
\end{array}\right)\right)
$$

where for $m=1,2,-m \neq m$

$$
\begin{aligned}
\mu_{q_{m}^{i}} & \equiv\left(\frac{1}{n}\right)\left\{\mu_{m}+\alpha_{m}(n-1)\left[s_{i}-\mu_{s}\right]\right\} \\
\mu_{q_{-m}^{i}} & \equiv\left(\frac{1}{n}\right)\left\{\mu_{-m}+\alpha_{-m}(n-1)\left[s_{i}-\mu_{s}\right]\right\}
\end{aligned}
$$

and

$$
\begin{aligned}
\sigma_{q_{m}^{i}} & \equiv\left(\frac{1}{n}\right) \sqrt{\alpha_{m}^{2}(n-1) \sigma_{s}^{2}+\sigma^{2}} \\
\sigma_{q_{-m}^{i}} & \equiv\left(\frac{1}{n}\right) \sqrt{\alpha_{-m}^{2}(n-1) \sigma_{s}^{2}+\sigma^{2}}
\end{aligned}
$$

and

$$
\rho^{i}=\frac{\alpha_{m} \alpha_{-m}(n-1) \sigma_{s}^{2}+\rho \sigma^{2}}{\sqrt{\left[\alpha_{m}^{2}(n-1) \sigma_{s}^{2}+\sigma^{2}\right]\left[\alpha_{-m}^{2}(n-1) \sigma_{s}^{2}+\sigma^{2}\right]}}
$$

Lemma 4. (i) If a vector $\boldsymbol{X}$ is distributed multivariate normal $N_{p}(\boldsymbol{\mu}, \Sigma)$, then any linear combination is normal: $\boldsymbol{a}^{\prime} \boldsymbol{X}=a_{1} X_{1}+\ldots a_{p} X_{p} \sim N\left(\boldsymbol{a}^{\prime} \boldsymbol{\mu}, \boldsymbol{a}^{\prime} \Sigma \boldsymbol{a}\right)$, including $a_{n}=0$. (ii) If $\boldsymbol{a}^{\prime} \boldsymbol{X} \sim N\left(\boldsymbol{a}^{\prime} \boldsymbol{\mu}, \boldsymbol{a}^{\prime} \Sigma \boldsymbol{a}\right)$ for every $\boldsymbol{a}, \boldsymbol{X}$ must be $N_{p}(\boldsymbol{\mu}, \Sigma)$.

Lemma 5. If $\boldsymbol{X}$ is distributed as $N_{p}(\boldsymbol{\mu}, \Sigma)$ then the q-linear combinations

$$
\boldsymbol{A}_{(q \times p)} \boldsymbol{X}_{(p \times 1)}=\left|\begin{array}{l}
a_{11} X_{1}+\ldots a_{1 p} X_{p} \\
a_{q 1} X_{1}+\ldots . a_{q p} X_{p}
\end{array}\right|
$$

are distributed as $N_{q}\left(\boldsymbol{A} \boldsymbol{\mu}, \boldsymbol{A} \Sigma \boldsymbol{A}^{\prime}\right)$. Also the $\boldsymbol{X}_{p \times 1}+\boldsymbol{d}_{p \times 1}$, where $\boldsymbol{d}$ is a vector of constats is distributed as $N_{q}(\boldsymbol{\mu}+\boldsymbol{d}, \Sigma)$.

Lemma 6. Given $\left(\begin{array}{l}X_{1} \\ X_{2}\end{array}\right) \sim N\left(\left(\begin{array}{l}\mu_{1} \\ \mu_{2}\end{array}\right),\left(\begin{array}{cc}\sigma^{2} & \rho \sigma \sigma \\ \rho \sigma \sigma & \sigma^{2}\end{array}\right)\right) \Rightarrow \mathbb{E}\left[X_{1} \mid X_{2}=x_{2}\right]=\mu_{1}+\rho \frac{\sigma}{\sigma}\left(x_{2}-\mu_{2}\right)$. 
Step 3. We have determined that the winning quantities are jointly normally distributed. Their conditional expectation is linear

$$
\begin{aligned}
\mathbb{E}\left[\boldsymbol{q}_{\boldsymbol{i},-\boldsymbol{m}}^{*} \mid q_{m}\right] & =\mu_{q_{-m}^{i}}+\rho^{i}\left(\frac{\sigma_{q_{-m}^{i}}}{\sigma_{q_{m}^{i}}}\right)\left(q_{m}-\mu_{q_{m}^{i}}\right) \\
\mathbb{E}\left[\boldsymbol{q}_{\boldsymbol{i},-\boldsymbol{m}}^{*} \mid q_{m}\right] & =\left(\frac{1}{n}\right)\left(\left\{\mu_{-m}+\alpha_{-m}(n-1)\left[s_{i}-\mu_{s}\right]\right\}-\left(\frac{\alpha_{m} \alpha_{-m}(n-1) \sigma_{s}^{2}+\rho \sigma^{2}}{\alpha_{m}^{2}(n-1) \sigma_{s}^{2}+\sigma^{2}}\right)\left\{\mu_{m}+\alpha_{1}(n-1)\left[s_{i}-\mu_{s}\right]\right\}\right) \\
& +\left(\frac{\alpha_{m} \alpha_{-m}(n-1) \sigma_{s}^{2}+\rho \sigma^{2}}{\alpha_{m}^{2}(n-1) \sigma_{s}^{2}+\sigma^{2}}\right) q_{m} \\
\mathbb{E}\left[\boldsymbol{q}_{\boldsymbol{i},-\boldsymbol{m}}^{*} \mid q_{m}\right] & =\left(\frac{1}{n}\right)\left[\left[\mu_{-m}-\alpha_{-m}(n-1) \mu_{s}\right]-\left(\frac{\alpha_{m} \alpha_{-m}(n-1) \sigma_{s}^{2}+\rho \sigma^{2}}{\alpha_{m}^{2}(n-1) \sigma_{s}^{2}+\sigma^{2}}\right)\left[\mu_{m}-\alpha_{1}(n-1) \mu_{s}\right]\right] \\
& +\left(\frac{1}{n}\right)(n-1)\left[\alpha_{-m}-\left(\frac{\alpha_{m} \alpha_{-m}(n-1) \sigma_{s}^{2}+\rho \sigma^{2}}{\alpha_{m}^{2}(n-1) \sigma_{s}^{2}+\sigma^{2}}\right) \alpha_{m}\right] s_{i} \\
& +\left(\frac{\alpha_{m} \alpha_{-m}(n-1) \sigma_{s}^{2}+\rho \sigma^{2}}{\alpha_{m}^{2}(n-1) \sigma_{s}^{2}+\sigma^{2}}\right) q_{m}
\end{aligned}
$$

\section{Proof of the Irrelevance Theorem}

\section{Statement $(i)$}

Consider first the case of fixed supply. The equilibrium quantity traded by agent $i$ is obtained by evaluating the demand schedule at the clearing price(s), which are easy to calculate given the strategies given in Lemma 1 and 2 at market clearing:

$$
\begin{aligned}
\bar{x}_{m}\left(\bar{p}_{m}^{*}, \bar{p}_{-m}^{*}, s_{i}\right) & =\alpha^{T}\left[s_{i}-\sum_{i} s_{i}\right]+\frac{Q_{m}}{n}=x_{m}\left(p_{m}^{*}, s_{i}\right) \\
\text { with } \alpha^{T} & \equiv\left(\frac{n-2}{n-1}\right)\left(\frac{1}{\lambda+\delta}\right)
\end{aligned}
$$

When supply is random, the agent follows the same ex-post equilibrium strategy when markets are centralized (Lemma 1). In a BNE of Lemma (3), the agent trades

$$
\begin{aligned}
x_{m}^{B N E}\left(p_{m}^{*}, s_{i}\right) & =\alpha^{B N E}\left[s_{i}-\sum_{i} s_{i}\right]+\frac{Q_{m}}{n} \\
\text { with } \alpha^{B N E} & =\left(\frac{n-2}{n-1}\right)\left(\frac{1}{\lambda+\delta \rho^{i}\left(\alpha^{B N E}\right)}\right)\left[1-\delta \alpha^{B N E}\left(\frac{1}{n}\right)(n-1)\left[1-\rho^{i}\left(\alpha^{B N E}\right)\right]\right]
\end{aligned}
$$

where $\rho^{i}\left(\alpha^{B N E}\right) \equiv \frac{\alpha^{2}(n-1) \sigma_{s}^{2}+\rho \sigma^{2}}{\alpha^{2}(n-1) \sigma_{s}^{2}+\sigma^{2}}$ for $\alpha=\alpha^{B N E}$ 
The equilibrium amount is identical to the one of the centralized market iff $\alpha^{B N E}=\alpha^{T}$. To prove that this can only hold iff $\rho=1$ or $\sigma=0$, I show that that condition (49) evaluated at $\alpha^{B N E}=\alpha^{T}$ does not hold iff $\rho \neq 1$ and $\sigma \neq 0 \Leftrightarrow \rho^{i}\left(\alpha^{T}\right) \neq 1$ :

$$
\begin{aligned}
\left(\frac{n-2}{n-1}\right)\left(\frac{1}{\lambda+\delta}\right) & \neq\left(\frac{n-2}{n-1}\right)\left(\frac{1}{\lambda+\delta \rho^{i}\left(\alpha^{T}\right)}\right)\left[1-\delta\left(\frac{n-2}{n-1}\right)\left(\frac{1}{\lambda+\delta}\right)\left(\frac{1}{n}\right)(n-1)\left[1-\rho^{i}\left(\alpha^{T}\right)\right]\right] \\
\left(\frac{\lambda+\delta \rho^{i}\left(\alpha^{T}\right)}{\lambda+\delta}\right) & \neq 1-\delta\left(\frac{n-2}{n-1}\right)\left(\frac{1}{\lambda+\delta}\right)\left(\frac{1}{n}\right)(n-1)\left[1-\rho^{i}\left(\alpha^{T}\right)\right] \\
n \lambda+n \delta \rho^{i}\left(\alpha^{T}\right) & \neq n(\lambda+\delta)-\delta(n-2)\left[1-\rho^{i}\left(\alpha^{T}\right)\right] \\
\rho^{i}\left(\alpha^{T}\right)[n \delta-\delta(n-2)] & \neq n \delta-(n-2) \delta \\
2 \rho^{i}\left(\alpha^{T}\right) \delta & \neq 2 \delta \\
\Leftrightarrow \rho^{i}\left(\alpha^{T}\right) & \neq 1 \text { since } \delta \neq 0 \text { by assumption. }
\end{aligned}
$$

Statement $(i i)$

Let $\sigma \neq 0$, and $\rho \rightarrow 1$. By definition of $\rho^{i}(\alpha) \rightarrow 1$ for any $\alpha$. Now this implies that

$$
\alpha^{B N E} \rightarrow \alpha^{T}
$$

The same is true when fixing $\rho \neq 1$ and $\sigma \rightarrow 0$. 